\title{
Protection Strategies for the Connection of Diode Rectifier-based Wind Power Plants to HVDC Interconnectors
}

\author{
Jaime Martínez-Turégano, Student Member, IEEE, Ricardo Vidal-Albalate, Salvador Añó-Villalba, \\ Soledad Bernal-Perez, Member, IEEE, Ramón Blasco-Gimenez, Senior Member, IEEE
}

\begin{abstract}
The connection of diode rectifier (DR) based wind power plants to existing or planned High Voltage dc (HVdc) interconnectors can lead to important savings on cost and system robustness. Since the DR station usually operates in a bipolar configuration, its connection to symmetric monopoles is particularly challenging. However, there are no published detailed studies on the protection of DR connection wind power plants to symmetric monopole interconnectors or even to bipolar interconnectors.

This paper includes the comparative study of five different protection strategies for such systems, including both solid and resistive DR station grounding and strategies with and without the use of dc-circuit breakers. An analytical study allows for the calculation of fault current during fault on-set for both half-bridge and hybrid Modular Multi-level Converter (MMC) stations. Using detailed Electromagnetic Transient (EMT) simulation studies, the different protection strategies are evaluated in terms of current, voltage and isolation requirements of each element, as well as the need for dc-circuit breakers, fast communication or larger surge arresters. Moreover, a distance fault detection algorithm is included for the wind turbine converters to distinguish between local ac-grid and dc-cable faults.

From the simulation results it is possible to conclude that DR high impedance grounding, together with wind turbine distance protection can be used for the protection of DR based offshore wind power plants connected to symmetric monopole interconnectors without requiring dc-circuit breakers.
\end{abstract}

Index Terms-HVdc transmission control, HVdc Diode Rectifiers, MMC station, Protection strategies in HVdc grids, Wind power generation, Multiterminal HVdc links.

\section{INTRODUCTION}

D IODE Rectifier (DR) stations have been proposed for the connection of off-shore Wind Power Plants (WPPs) to High Voltage dc (HVdc) links, [1], [2]. The main benefits of diode rectifier stations when compared to Voltage Source Converter (VSC) stations are lower cost and footprint, and higher efficiency and robustness [3]. Transmission losses can be reduced by $20 \%$ with respect to VSC links [4], [5].

This work was supported by the Spanish Ministry of Economy and EU FEDER Funds under grant DPI2017-84503-R. Project partially funded by the EU through the Comunitat Valenciana 2014-2020 European Regional Development Fund (FEDER) Operating Program (grant IDIFEDER/2018/036). This project has received funding from the European Union's Horizon 2020 research and innovation program under grant agreement No. 691714.

J. Martínez-Turégano, S. Añó-Villalba, S. Bernal-Perez and R. BlascoGimenez are with Universitat Politècnica de València, 46022 València, Spain (email: jaumartu@upv.es, sanyo@die.upv.es, sbernal@die.upv.es, rblasco@upv.es).

R. Vidal-Albalate is with Universitat Jaume I, 12071 Castelló de la Plana, Spain (e-mail: rvidal@uji.es).
Manufacturers claim that the total cost of the transmission system can be reduced by $30 \%$ whereas the total topside volume can be reduced by $80 \%$, compared to existing VSCHVdc transmission systems [6].

On the other hand, particularly in Northern Europe, a large number of interconnectors are planned in close proximity to off-shore wind power plant development sites. Therefore, the use of the HVdc interconnectors for both energy trading and WPP connection can lead to important installation savings while increasing overall system redundancy.

DC faults in Modular Multi-level Converter (MMC) based HVdc links have been extensively studied, mainly by means of simulation models [7], [8]. [7] compares the use of ac and dc breakers to isolate dc faults and [8] proposes to use full bridge (FB) cells to interrupt the fault currents at the expense of higher losses during normal operation. Mathematical models have been proposed to estimate the maximum fault currents and their steady-state value for both monopolar symmetrical [9], [10] or bipolar [10], [11] HVdc links. [9] and [11] provide analytical expressions to obtain the value of the fault currents, however, the overvoltages that can appear in the system, specially in pole-to-ground faults in symmetrical monopolar grids, are not studied. Moreover, none of them considered the effect of Diode Rectifier Units (DRUs) on HVdc faults. Even though half bridge (HB) MMCs behave as a diode rectifier when blocked, they use ac side point-star reactors for grounding, whereas Line Commutated Converter (LCC) rectifier stations typically use dc-side low impedance grounding. Therefore, these works did not consider the effects of specific station grounding or wind power plant control on over-currents and over-voltages during faults.

Specific studies have been carried out for hybrid LCC-VSC systems. Operation and fault ride through studies of hybrid LCC-VSC systems, such as the Wudongde multi-terminal project, have been presented in [12], [13], [14]. A monopolar configuration, consisting on a single LCC rectifier station and two MMC inverter stations, used high power diodes to prevent the half-bridge MMC stations from feeding the faults [12]. Fault currents were cleared by acting on the commutation angle of the LCC rectifier station. This study was extended from a single LCC station to a bipolar system including two MMC inverter stations, an LCC rectifier station and an LCC inverter stations. The protection strategy also included the use of high power diodes and fault current blocking by the thyristor rectifier stations [15]. These strategies are 
not applicable to interconnectors since the MMC stations should operate with bi-directional power flows, therefore diode protection is not feasible and the LCC diode rectifier stations cannot be used to clear the fault currents.

The protection strategies for the Wudongde project includes the use of fast disconnectors and hybrid full-bridge half-bridge MMC stations with fault blocking capability in a bipolar configuration, considering a single LCC rectifier station and two MMC inverter stations [13], [14]. The combined use of hybrid MMC stations and LCC station phase angle control, allow for fast fault current reduction during dc-faults, at the expense of higher system losses. However, since the Wudonge project uses overhead lines, the likelihood of dc faults is much larger than when using submarine cables, so the use of hybrid MMC stations is justified.

The aforementioned studies considered bipolar systems, however, most VSC interconnectors are symmetric monopoles. In these installations, fault response is particularly challenging, as pole to ground faults lead to large healthy pole overvoltages [16]. Moreover, pole re-balancing is needed due to the use of high impedance grounding for the MMCs [17]. The authors of [18] did show the technical viability of a protection and pole re-balancing system consisting of dccircuit breakers (dcCB) and dc choppers using actual control and protection replicas for all the elements, including converter stations control replicas. However, the use of dc choppers and dcCBs, is very costly, particularly for off-shore HVdc stations. Moreover, it would undermine the simplicity and robustness of the use of a diode rectifier station.

Faults in hybrid LCC-VSC HVdc systems with Diode Rectifier-connected Wind Power Plants (DR-WPP) have been previously studied [4], [19], [20], [21]. However, [4] considered mainly the efficiency studies, with only marginal fault studies in monopolar point-to-point systems. This work was extended to multi-terminal bipolar systems [19]. In both cases, averaged models of the VSC converters were used and the fault studies carried out did not include any new proposal for fault response co-ordination between different elements. Other studies used either full bridge converters [20] or hybrid MMC stations [21]. The use of fault blocking converters makes fault handing relatively easier, at the expense of higher costs and losses, moreover [21] only considered off-shore ac faults.

Therefore, existing literature did not cover in detail the protection of WPP-DR wind power plants when connected to $\mathrm{HVdc}$ interconnectors. Moreover, the effects of DR station grounding or Wind Turbine Generator (WTG) distance protection to distinguish between local ac-grid and HVdc cable faults has not been covered in existing literature.

Therefore, the contributions of this paper are:

- Proposal and comparative evaluation of different protection strategies for the connection of DR-WPP to HVdc interconnectors (i.e. a type-1 HVdc station connected to either type-3 or type-4 on-shore stations [16]).

- Study of high impedance grounding on the LCC diode rectifier station when connecting to symmetric monopolar MMC stations.

- Develop a WTG distance protection strategy that allows WTGs to detect if a fault is located in the off-shore ac- grid or in the HVdc cables and act accordingly.

This paper includes the study of 5 different strategies for the protection of the combined $\mathrm{HVdc}$ interconnector and DRUconnected wind power plant against $\mathrm{HVdc}$ faults, namely:

1) Solid DRU grounding. Baseline scenario with MMCs connected as a symmetric monopole and the DRU with a solid connection to ground. Fault clearing using dcCBs.

2) Resistive DRU-HVdc grounding. Resistive grounding to limit fault currents. Fault clearing using dcCBs.

3) Grounding resistor and WPP blocking. Includes WTG detection of HVdc faults and WPP blocking. Fault clearing using dcCBs.

4) WTG distance protection and MMC blocking. Includes WTG detection of HVdc faults and WPP and HVdc blocking. dcCBs not used.

5) Hybrid MMC with full fault blocking capability. Bipolar configuration. No dcCBs required.

These alternatives are analysed regarding the overvoltage and overcurrent in cables and converters, surge arrester dissipated energy and fault clearing times. It is shown that option 4 is the less costly option, at the expense of somehow larger clearing times and higher energy dissipated in surge arresters.

\section{INTERCONNECTOR WITH INTERMEDIATE WPP}

The proposed system is shown in Fig. 1 and consists of a typical HVdc interconnector with an additional DR-based terminal for the connection of the off-shore WPP. The other two terminals of the HVdc system are two symmetrical monopolar MMC converters (HB) to connect to the corresponding two onshore grids for protection strategies 1-4, whereas two hybrid bipolar MMC converters are used for strategy 5. The on-shore stations are controlled using standard master-slave control, where one of the stations controls the interconnector $\mathrm{HVdc}$ voltage and the other operates on active power reference.

The off-shore WPP consists of three clusters with fifty 8 MW-rated wind turbines (400 MW each WPP). The wind turbines are of variable speed with fully-rated converters. The diode rectifier $\mathrm{HVdc}$ station consists of three platforms. Each platform has two series connected 12-pulse diode based rectifiers with the corresponding ac and dc filters. The WTGs are all grid forming and include P-V and Q- $\omega$ droops, commonly used for distributed control of grid forming WTGs when connected to DR stations [1].

The considered scenario has enough complexity, so the results are representative of a realistic fault response. The interconnector is a VSC-HVdc $300 \mathrm{~km}, \pm 320 \mathrm{kV}$ and $1.2 \mathrm{GW}$. Power and voltage ratings correspond to recently completed $\mathrm{HVdc}$ projects. The total cable length $(300 \mathrm{~km})$ is based on the CobraCable link, and represents some of the longest $\mathrm{HVdc}$ interconnectors in Europe, therefore, considered cable charge is in the upper limit of existing installations. The DRU system consists of a three platform installation, with parallel ac connection and series dc connection, including an ac ring bus cable [3]. Diode rectifier valves include the effects of snubbers and grading resistors. The DR ac-filters and the surge arresters are also included in the model, as their behaviour is important during fault onset and fault recovery. 


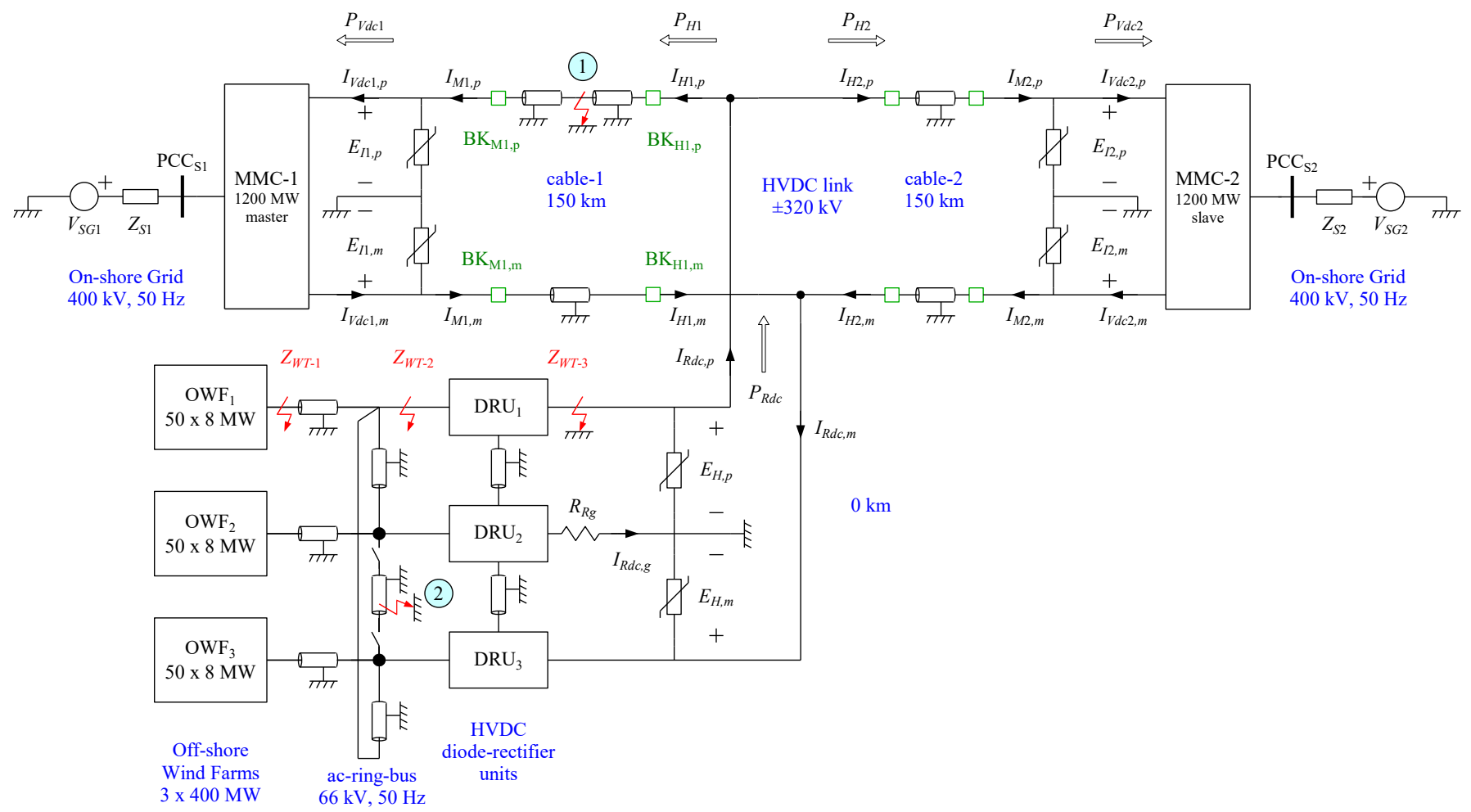

Fig. 1. Overall system diagram including main components, location of faults (1) and (2), and apparent impedances $Z_{W T}$.

TABLE I

MMC DATA

\begin{tabular}{lclc}
\hline Parameter & Value & Parameter & Value \\
\hline dc voltage $(\mathrm{kV})$ & \pm 320 & ac-grid voltage $(\mathrm{kV})$ & 400 \\
Active power $(\mathrm{MW})$ & 1200 & $T_{R}(\mathrm{kV})$ & $333 / 400$ \\
Reactive power $(\mathrm{MVAr})$ & 415 & $T_{R}$ power $(\mathrm{MVA})$ & 1300 \\
Levels & 401 & $L_{T_{R}}(\mathrm{pu})$ & 0.18 \\
Arm inductance $(\mathrm{mH})$ & 41.7 & $R_{T_{R}}(\mathrm{pu})$ & 0.01 \\
$C(\mathrm{mF})$ & 14.5 & $L_{g}(\mathrm{H})$ & 5000 \\
$v_{c}(\mathrm{kV})$ & 1.6 & $R_{g}(\Omega)$ & 5000 \\
\hline
\end{tabular}

The studied dc-faults are located in cable-1, i.e. the section connecting the DR station to the voltage controlling MMC. This is a more challenging scenario regarding dc faults. As for off-shore ac-grid faults, a ring bus fault is considered, as it is a location that would lead to the highest fault currents within the off-shore ac-grid.

The HVdc link, with a symmetrical monopolar configuration, uses a star-point reactor connected on the ac-side to provide a ground reference. The MMCs parameters, which are based on the France-Spain link [22], are presented in Table I.

\section{Analytical Study OF MMC-DR System DC FAULTS}

This section includes the analytical study of dc-fault currents and voltages for hybrid DR-VSC systems considering DR dc-side impedance grounding and both monopolar and bipolar MMC converter stations.

The behaviour of MMC-1 to a solid pole-to-ground cable-1 fault is analysed considering the equivalent circuit in Fig. 2,

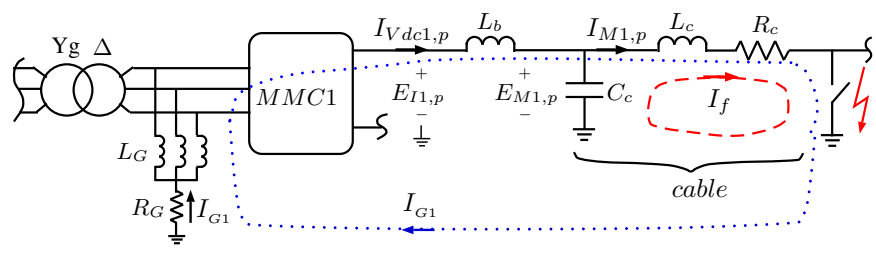

Fig. 2. Equivalent circuit of the on-shore MMC stations.

where MMC-1 is not blocked. During the first milliseconds, the response is mainly influenced by cable discharge (red path), since the contribution of the ac-side current is limited by the inductive components of the ac-grid (lines, transformers), the MMC arm reactors and the dc-breaker reactor. Additionally, the dc-side neutral voltage is no longer zero but is displaced towards negative values which provokes that a fault current starts flowing through the ac-side star-point reactor as shown with the blue path.

This study is only valid for the first 5-7 ms, i.e., when the system response is hardly influenced by the system controls due to both fault detection delays and control delay times. However, this analysis can help estimating the maximum fault currents that the power stations, cables and dc-breaker need to withstand.

From Fig. 2, we have:

$$
\begin{aligned}
E_{M 1, p} & =\left(-L_{c} C_{c} \frac{d^{2} E_{M 1, p}}{d t^{2}}-R_{c} C_{c} \frac{d E_{M 1, p}}{d t}\right) \\
& +\left(L_{c} \frac{d I_{V d c 1, p}}{d t}+R_{c} I_{V d c, p}\right)
\end{aligned}
$$



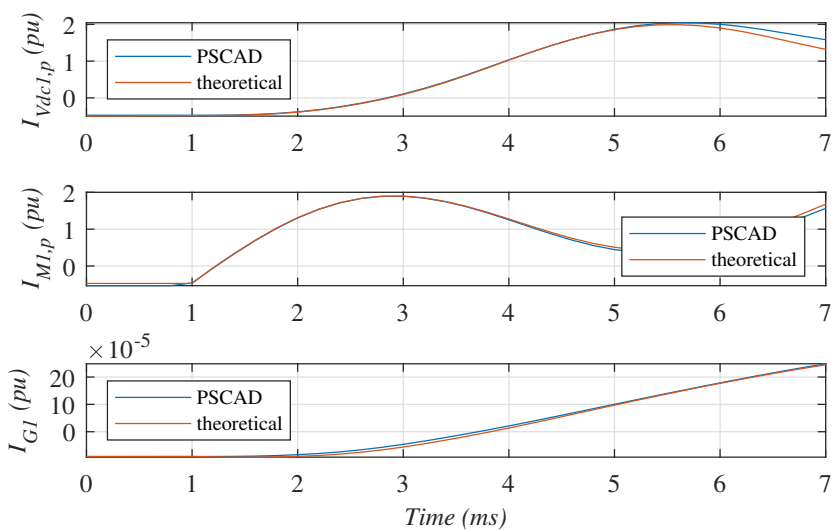

Fig. 3. Comparison of the theoretical and PSCAD currents when the MMC is not blocked. From top to bottom: MMC-1 dc-current (positive pole); cable-1 current (positive pole); MMC-1 star-point reactor current.

where the first term corresponds to the cable discharge and the second to the MMC contribution. The cable discharge dynamics are [23]:

$$
I_{f}=\frac{E_{M 1, p 0}}{\omega_{c} L_{c}} e^{-\frac{R_{c}}{2 L_{c}} t} \sin \left(\sqrt{\frac{1}{L_{c} C_{c}}-\left(\frac{R_{c}}{2 L_{c}}\right)^{2}} t\right)
$$

where $E_{M 1, p 0}$ is the initial pole-to-ground voltage. The dynamics of MMC contribution in (1) are (assuming it is not blocked):

$$
\begin{aligned}
& L_{b} \frac{d I_{V d c 1, p}}{d t}=E_{I 1, p}-E_{M 1, p}= \\
& \quad-R_{G} I_{G 1}-L_{G} \frac{d I_{G 1}}{d t}+V_{c a p}-E_{M 1, p}
\end{aligned}
$$

where $E_{I 1, p}$ is the dc voltage at the MMC dc-side and $V_{\text {cap }}$ is the dc-voltage inserted by the upper MMC arms, which can be obtained from the submodule capacitor discharge dynamics:

$$
C_{e q} \frac{d V_{c a p}}{d t}=I_{V d c 1, p}-I_{V d c 1, p 0}
$$

where $C_{e q}$ is the equivalent capacitance of the MMC and $I_{V d c 1, p 0}$ is the current at the moment of the fault onset.

The dynamics of $I_{G 1}$ are:

$$
E_{n}=L_{G} \frac{d I_{G 1}}{d t}+R_{G} I_{G 1} \approx E_{I 1, p 0}-E_{I 1, p}
$$

where $E_{I 1, p 0}$ is the nominal pole-to-ground voltage and $E_{n}$ is the dc-side neutral voltage $\left(E_{n}=E_{I 1, p}-E_{I 1, n} \approx\right.$ $E_{I 1, p 0}-E_{I 1, p}$ during the fault). Cable, MMC arm and dcbreaker impedances have been neglected as ac-side grounding impedance can be three to four orders of magnitude greater.

Fig. 3 shows the comparison between theoretical and simulation fault currents, showing an underdamped response whose frequency is given by (2).

If $\mathrm{dcCBs}$ are used as protection system, the surge arrester of the dcCB includes a voltage-dependent resistance in the circuit which is added to $R_{G}$ in (3) and (5). Fig. 4 shows both the theoretical and PSCAD response when the dc-breaker isolates the fault at $t=5.3 \mathrm{~ms}$ approximately. In the theoretical study, a constant average value has been considered, for this reason, the steady-state values of $I_{G 1}$ differ. Notwithstanding,
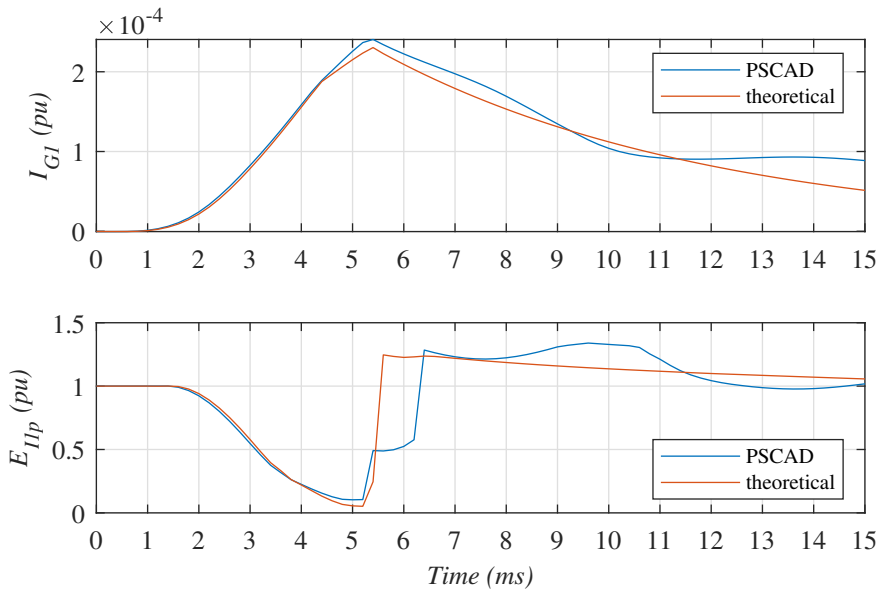

Fig. 4. Comparison of the theoretical and PSCAD results when the dc-breaker is opened. From top to bottom: MMC-1 star-point reactor current; MMC-1 dc-voltage (positive pole).
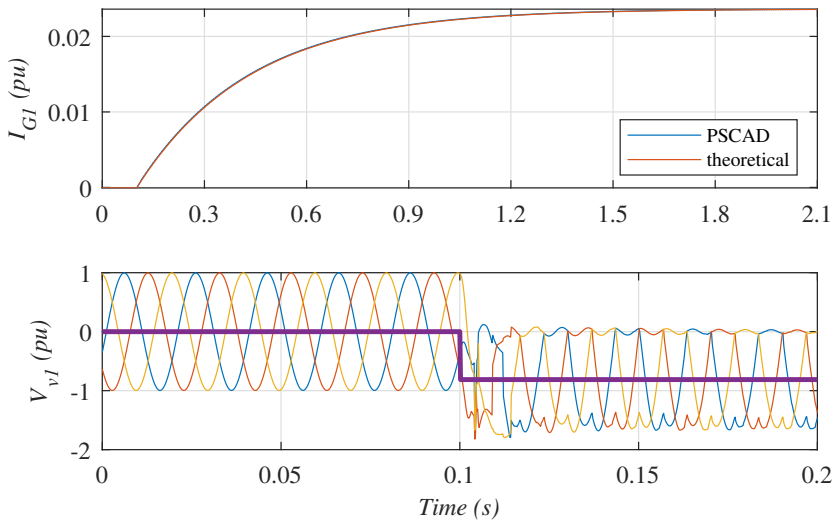

Fig. 5. Comparison of the theoretical and PSCAD results when the MMC is blocked. From top to bottom: MMC-1 star-point reactor current; MMC-1 ac-voltage.

the analytical expressions allow for a good representation of maximum fault currents and voltages.

If the MMC is blocked as a protection system, it behaves like an uncontrolled half-wave rectifier that creates the following dc voltage.

$$
E_{n}=E_{b l k}=\frac{3}{\pi \sqrt{2}} V_{v}
$$

where $V_{v}$ is the rms value of the voltage at the ac-side of the MMC. In steady-state, the grounding fault current is:

$$
I_{G 1}=\frac{E_{b l k}}{R_{G}}
$$

Although the MMC behaves as a rectifier and keeps feeding the fault, the current $I_{G 1}$ is limited to small values when a high-impedance grounding is used, [22]. Fig. 5 shows the grounding fault current $I_{G 1}$ and the MMC ac-side voltages $V_{v 1}$, which present a common mode voltage after blocking the converter. Due to the fault, the positive dc pole voltage is zero; therefore, the dc voltage is displaced towards negatives values. This, in turn, provokes a common mode voltage on the MMC ac-side, which is not solidly grounded (see Fig. 2). 


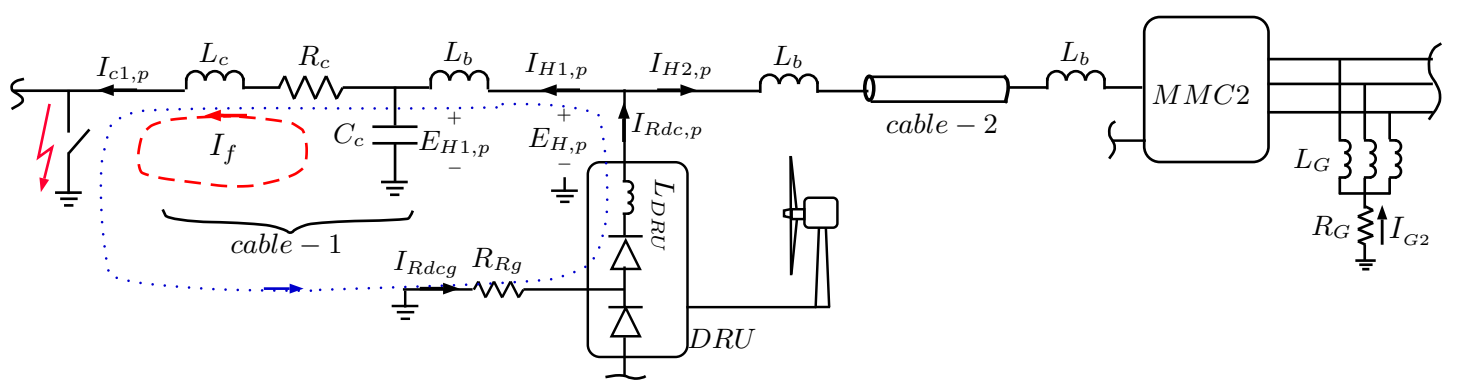

Fig. 6. Equivalent circuit of the DRU station.

The previous analysis can be extended to the other MMC station and to the DRU, Fig. 6 . The cable voltage is:

$$
\begin{aligned}
E_{H 1, p} & =\left(-L_{c} C_{c} \frac{d^{2} E_{H 1, p}}{d t^{2}}-R_{c} C_{c} \frac{d E_{H 1, p}}{d t}\right) \\
& +\left(L_{c} \frac{d I_{H 1, p}}{d t}+R_{c} I_{H 1, p}\right)
\end{aligned}
$$

where the first terms correspond to the cable discharge and the second terms correspond to the contribution of the DRU and the MMC-2, where $I_{H 1, p}$ is:

$$
I_{H 1, p}=I_{R d c, p}-I_{H 2, p}
$$

The current $I_{H 2, p}$ due to the discharge of the cable-2 and the contribution of the MMC-2 can be obtained as per (2). The WPP fault current $I_{R d c, p}$ is computed considering the WPP as a constant current source that feeds the fault current:

$$
I_{R d c 1, p}=I_{R d c 1, p 0}+I_{R d c, g}
$$

where $I_{R d c 1, p 0}$ is the DRU current at the fault onset and $I_{R d c, g}$ is the fault current flowing through the DRU grounding resistor. The voltage at the DRU terminals is:

$$
E_{H, p}=E_{H 1, p}+L_{b} \frac{d I_{H 1, p}}{d t}
$$

During normal operation, the dc-side neutral voltage $E_{n, D R U}=E_{H, p}-E_{H, n}$ is zero, as both poles have the same voltage. However, after the fault onset, the voltage of the positive pole drops whereas the voltage of the negative pole increases. This causes a fault current $I_{R d c, g}$ to flow through the DRU grounding (blue loop in Fig. 6):

$$
\begin{gathered}
E_{n, D R U}=\left(R_{c}+R_{R g}\right) I_{R d c, g}+\left(L_{c}+L_{b}+L_{D R U}\right) \frac{d I_{R d c, g}}{d t} \\
E_{n, D R U} \approx E_{H, p 0}-E_{H, p}
\end{gathered}
$$

where $E_{H, p 0}$ is the nominal pole-to-ground voltage.

Fig. 7 shows the evolution of the cable discharge current, the DRU fault current and the DRU dc-side grounding fault. During the first six milliseconds the theoretical and the PSCAD results present a good agreement. After that time, the error increases since the response of the MMC and WPP controllers has not been taken into account in the analysis.

For a bipolar HVdc system, which has two MMCs with midpoint grounded at each converter node, a pole-to-ground fault collapses the dc voltage to zero since it is a short-circuit between the MMC dc terminals, Fig. 8. As in the symmetrical
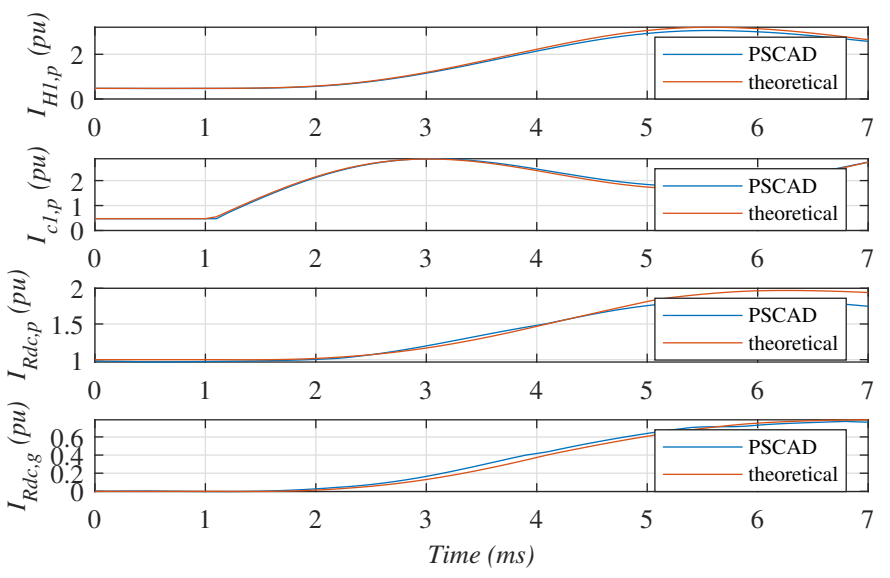

Fig. 7. Comparison of the theoretical and PSCAD currents of the DRU. From top to bottom: DRU to cable-1 dc-breaker current (positive pole); cable-1 current; DRU dc-current (positive pole); DRU ground current.

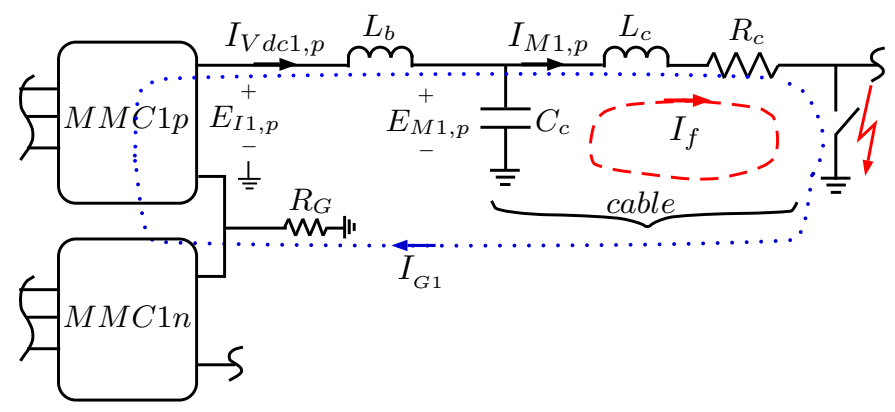

Fig. 8. Equivalent circuit of the on-shore MMC stations for a bipolar HVdc grid.

monopolar configuration, two fault paths can be identified. The red path in Fig. 8 corresponds to the cable discharged, which has already analyzed in (1) and (2). The second current path (blue loop) corresponds to the fault fed from the acside. Same analysis as in the case of monopolar symmetrical configuration can be carried out (equations (3)-(5)). However, bipolar $\mathrm{HVdc}$ grids are usually solidly grounded $\left(R_{G}=0\right)$ so the cable resistance and inductance cannot be neglected as in the previous case [24]. Therefore, (3)-(5) become:

$$
\begin{aligned}
& L_{b} \frac{d I_{V d c 1, p}}{d t}=E_{I 1, p}-E_{M 1, p}=-R_{G} I_{G 1}- \\
& -L_{M M C} \frac{d I_{G 1}}{d t}+V_{c a p}-E_{M 1, p}
\end{aligned}
$$



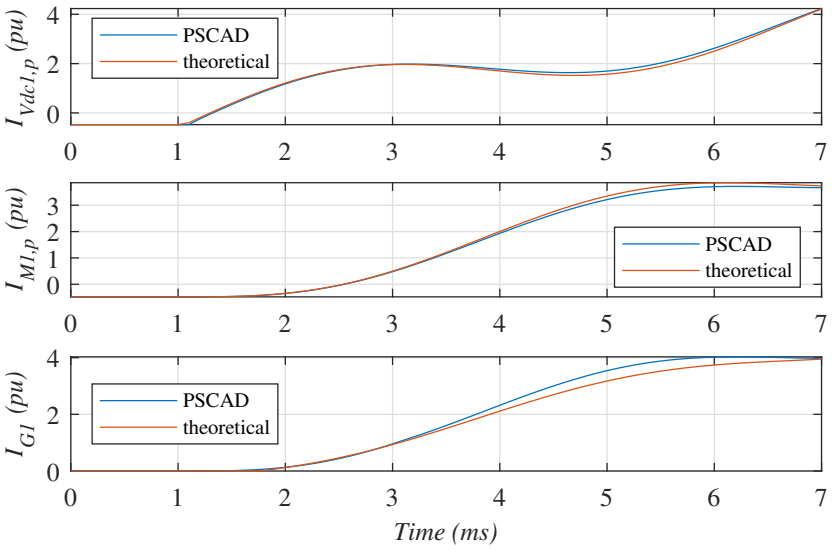

Fig. 9. Comparison of the theoretical and PSCAD currents for a bipolar HVdc grid. From top to bottom: MMC-1 dc-current (positive pole); cable-1 current (positive pole); MMC-1 ground current.
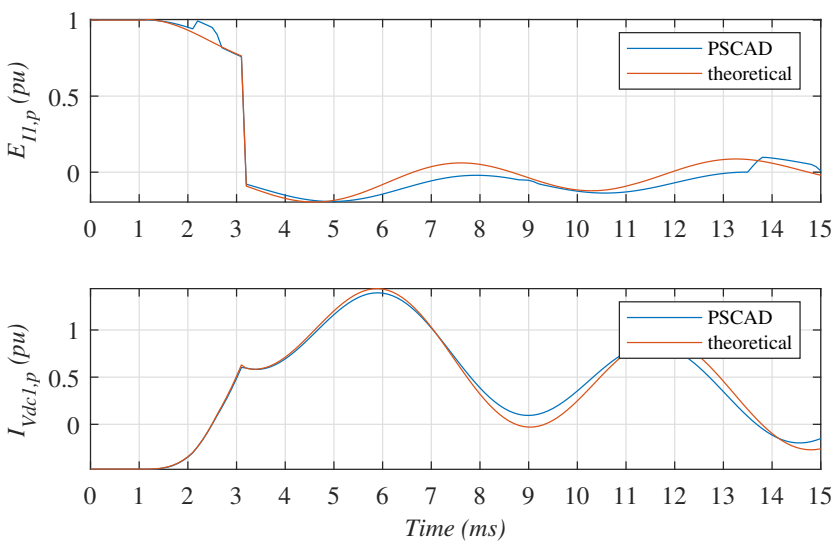

Fig. 10. Comparison of the theoretical and PSCAD currents for a bipolar HVdc grid using hybrid MMCs. From top to bottom: MMC-1 de-voltage (positive pole); MMC-1 dc-current (positive pole).

where $L_{M M C}$ is the equivalent $\mathrm{MMC}$ inductance $\left(L_{M M C}=\right.$ $2 L_{\text {arm }} / 3$ ), being $L_{\text {arm }}$ the inductance of each MMC arm.

$$
\begin{gathered}
C_{e q} \frac{d V_{c a p}}{d t}=I_{V d c 1, p}-I_{V d c 1, p 0} \\
E_{I 1, p}-L_{c} \frac{d I_{f}}{d t}-R_{c} I_{f}=\left(L_{c}+L_{M M C}\right) \frac{d I_{G 1}}{d t}+ \\
+\left(R_{G}+R_{c}\right) I_{G 1}
\end{gathered}
$$

Fig. 9 shows the comparison between theoretical and simulated fault currents when no actions are taken to limit the fault currents.

The fault current could be limited by using a high impedance grounding on the dc-side. Alternatively, the MMC can control the dc current by adjusting the dc voltage at the MMC terminals. In this case, a hybrid MMC using $\mathrm{HB}$ and FB cells is needed given that the MMC arms have to generate negative voltages. For this purpose, the dc voltage reference is changed to zero and the MMC changes to dc current current control. In this case, the voltage $E_{I 1, p}$ changes to 0 in the previous analysis once the fault is detected. Fig. 10 shows the results when a hybrid MMC is used to block the fault currents.

This section has included the theoretical analysis for the fault current and fault voltages for systems consisting on Diode
Rectifiers with resistive grounding and for both symmetrical and bipolar MMC stations. The expressions have been validated by means of EMT simulations and allow to calculate maximum fault currents and voltages for the considered configurations.

\section{WTG Distance Protection}

This section includes a description of the proposed distance protection strategy so WTGs can distinguish, by using only local measurements, if a fault is located at the off-shore ac grid or at the dc-cable.

WTG control can contribute to reducing overcurrents and overvoltages during faults [23], [21], [25]. However, WTG control needs to distinguish between off-shore ac-grid faults and HVdc faults. The reason being that, for off-shore ac-grid faults, the WTGs are feeding the fault and, hence, they can detect when the fault is cleared. However, for HVdc faults, the WTGs will reduce the ac-grid voltage so the diode rectifier stops conducting and the WTG does not contribute to steady state HVdc fault currents. Therefore, the WTGs cannot know, by themselves, that the HVdc fault has been cleared and they will require a command from the protection co-ordination system to resume active power injection.

Fig. 11 shows the apparent impedances $\left(\frac{V_{W T G}}{I_{W T G}}\right)$ seen from a WTG when the fault is located at different places: high voltage side of the WTG transformer $\left(Z_{W T-1}\right)$, DRU station ac-side $\left(Z_{W T-2}\right)$, and DRU station dc terminals $\left(Z_{W T-3}\right)$, as shown in Fig. 1. At $50 \mathrm{~Hz}$, there is a clear difference between the apparent impedance seen by the WTGs for closest and furthest off-shore ac-grid short circuits and HVdc grid short circuits. Therefore, the WTG can distinguish between off-shore ac faults and HVdc faults. From Fig. 11, the corresponding detection limits are:

- Off-shore ac grid: apparent admittance $\left|I_{W T G}\right| /\left|V_{W T G}\right|$ larger than 4 pu.

- HVdc grid: apparent admittance between $1.25 \mathrm{pu}$ and 3.5 pu.

However, the impedance difference between short circuits in different parts of the off-shore ac-grid is very small. The same can be said about short circuits in different locations of the HVdc cables. Therefore, while detecting if the fault is in the ac-grid or in the dc-grid is relatively straight forward, detecting the exact location of ac or HVdc faults using the proposed method is not.

\section{HVdc Fault Protection Strategies}

This section includes the study of the 5 different strategies for $\mathrm{HVdc}$ cable fault protection and recovery, which have been listed in the Introduction. The first 4 strategies consider a symmetric monopole, whereas the last one considers a bipolar configuration.

The performance of each protection strategy is evaluated by means of detailed EMT simulations. To ensure results as close as possible to an actual HVdc system, the EMT simulations carried out used HVdc frequency dependant cable models based on a geometry verified by manufacturers. WTG converter models have also been validated to behave in the 

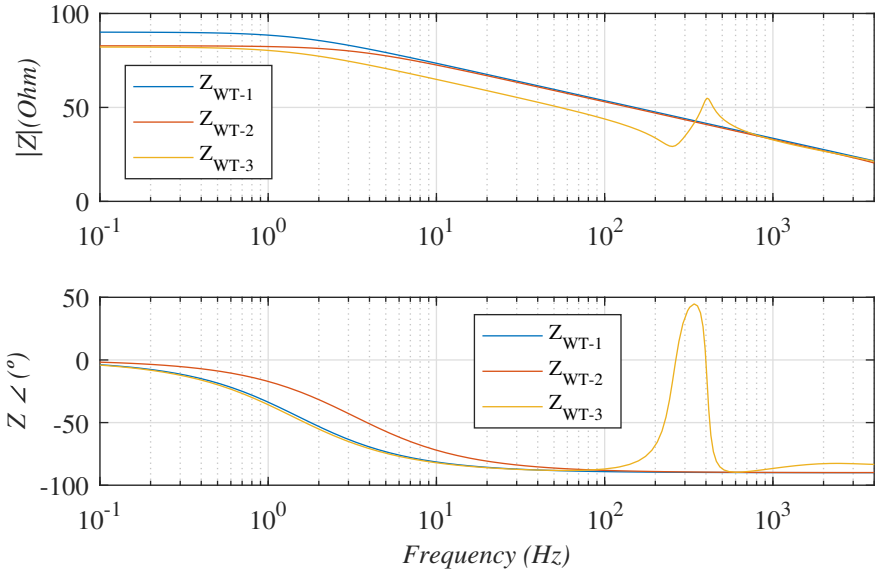

Fig. 11. Impedance seen by the WTGs for different fault locations.

same way as current commercial type-4 WTG converters, controllers use a control-software-in-the-loop approach, so delays and possible numerical issues are representative of an actual wind turbine converter controller. MMC simulations include transformers, grounding and individual cell modelling based on existing operational interconnectors. System parameters are included in Appendix A.

The dcCBs are located at both $\mathrm{HVdc}$ cable ends and are shown as green squares in Fig. 1. The fault current at any of the DRU poles $\left(I_{R d c}\right)$ is cleared when the corresponding cable current $I_{H}$ is cleared. For the scenarios where dcCBs are not used, they are substituted by disconnectors placed at the same locations as the dcCBs.

All dc cable fault studies assume a fault at the mid-point of the positive pole cable connecting MMC1 to the DRU-HVdc converter, which corresponds to fault 1 in Fig. 1.

MMC-1 is initially controlling the HVdc voltage (master), whereas MMC-2 and the OWPP are controlled to follow an active power set point. Once the fault is cleared, MMC-2 switches to voltage control mode.

For all the following fault studies, the DRU connected WPP is initially generating a 1 pu power, whereas MMC- 2 has an active power setpoint equal to $0.5 \mathrm{pu}$ and, hence, MMC- 1 is drawing the remaining 0.5 pu power being injected by the WPP. When the fault is detected, the dc-breakers disconnect the faulty DC cable (both poles) isolating MMC-1, and MMC2 turns to control the DC voltage $\left(E_{I 2}\right)$. At this stage, the WPP curtails its active power production to $0.5 \mathrm{pu}$, in this way the impact of a cable-1 fault on on-shore ac grid 2 is minimised. The DR station can easily detect if the fault has been in cable- 1 or cable-2 and then send the corresponding power curtailment signal to the WPP controller.

The total clearing time for the considered dcCBs is $5 \mathrm{~ms}$ from fault onset to zero dc current [18], [26].

\section{A. Fault response with solid DRU-MMC grounding}

In symmetric monopole configurations, the high ac-side grounding impedance of the MMC stations lead to relatively small short-circuit currents, at the expense of healthy pole overvoltage, that might require the use of dc-choppers for pole voltage re-balancing [18].
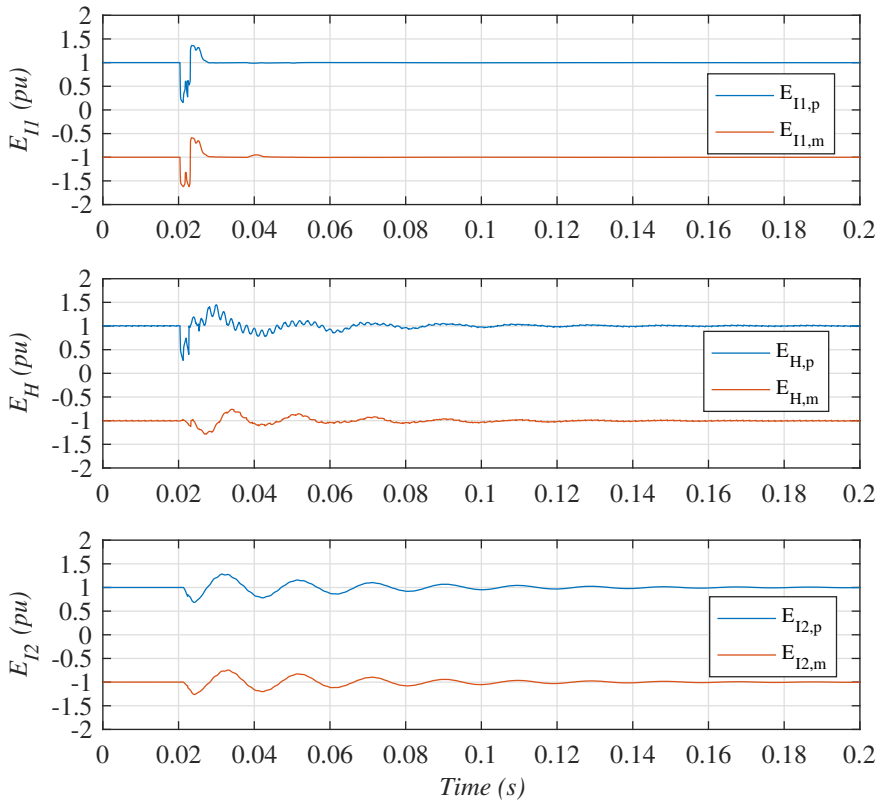

Fig. 12. Strategy 1: Converter terminal voltages (pu). From top to bottom: MMC-1 dc-voltages; DRU dc-voltages; MMC-2 dc-voltages.
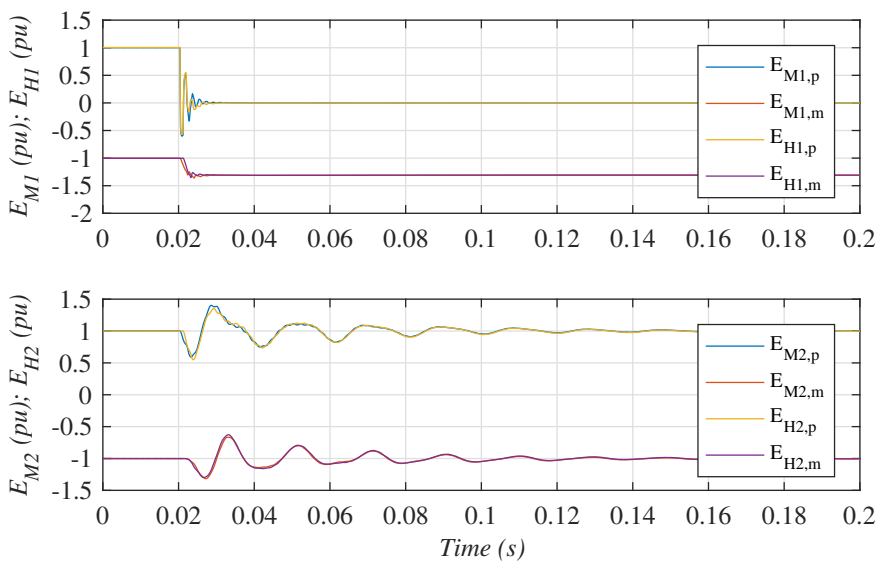

Fig. 13. Strategy 1: Cable voltages (pu). From top to bottom: cable-1 voltages; cable-2 voltages.

The use of a solid ground for the DRU station does away with the need of dc-chopper for pole voltage re-balancing, at the expense of much larger short-circuit currents.

Fig. 12 shows the voltages at the terminals of each converter for a positive pole-to-ground fault at $t=0.02 \mathrm{~s}$. The fault is detected and the corresponding dcCBs $\left(\mathrm{BK}_{\mathrm{M} 1, \mathrm{pm}}\right.$ and $\mathrm{BK}_{\mathrm{H} 1, \mathrm{pm}}$ in Fig. 1) clear the fault in $5 \mathrm{~ms}$ and both cable poles are disconnected permanently. At this stage, MMC-2 switches to voltage control mode and both MMC-2 and DRU voltages return to their pre-fault values in less than $100 \mathrm{~ms}$.

Fig. 13 shows the cable voltages at both ends of each cable. The top graph corresponds to the cable from MMC-1 to DRU and clearly shows that the voltage of the positive pole goes to zero as a result of the fault. The negative pole voltage is limited by the surge arrester and reaches $-1.4 \mathrm{pu}$ when the dcCBs are opened. On the other hand, the cable from the DRU to MMC-2 returns to $\pm 1 \mathrm{pu}$ voltage once the fault is cleared. 

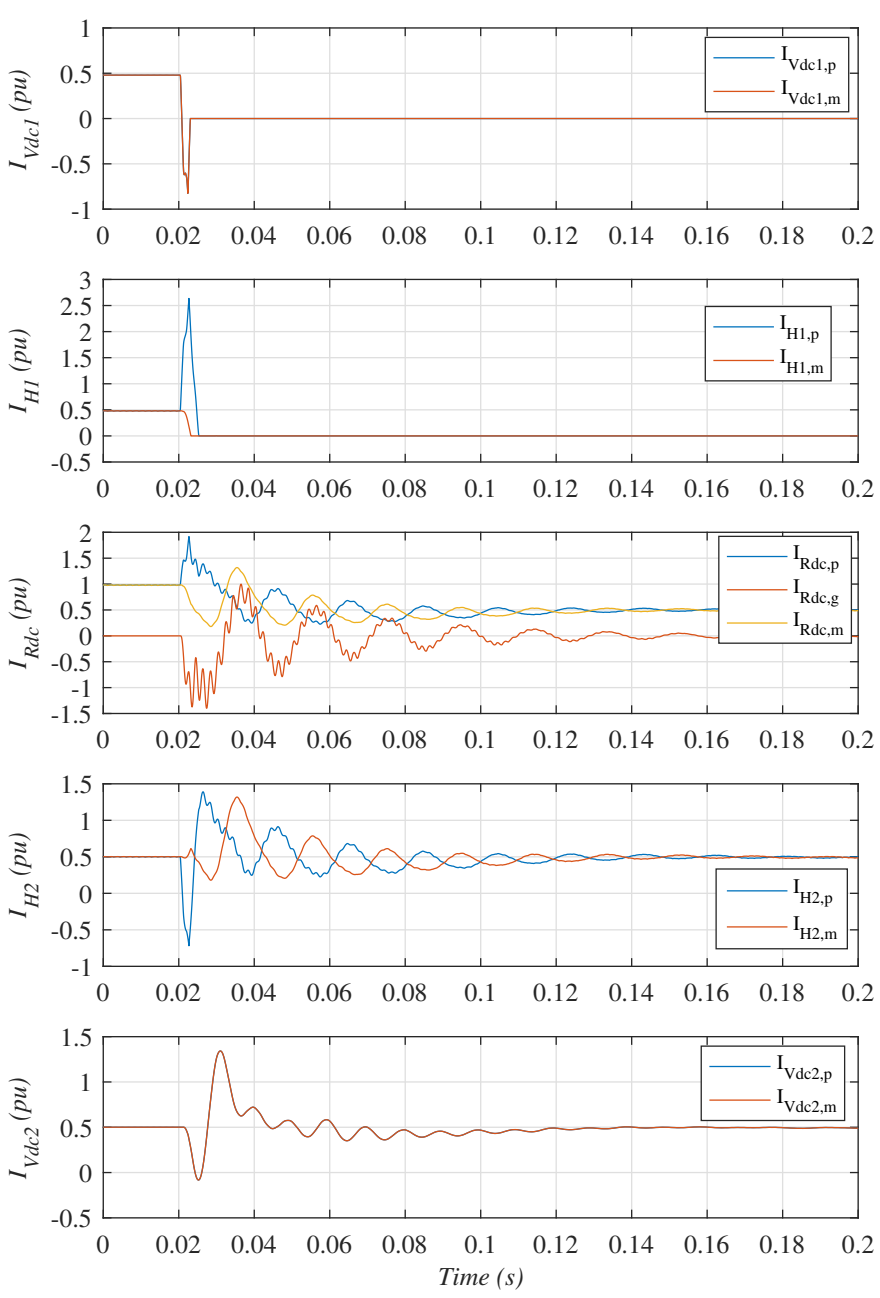

Fig. 14. Strategy 1: HVdc currents (pu). From top to bottom: MMC-1 dccurrents; DRU to cable-1 dc-breaker currents; DRU dc-currents; DRU to cable2 dc-breaker currents; MMC-2 dc-currents.

The currents during the short circuit are shown in Fig. 14. The MMC-1 dc-side current $I_{V d c 1}$ becomes negative, as it is flowing now through the HB cell diodes. After approximately $3 \mathrm{~ms}$, the dcCB opens and the current now flows through the dcCB surge arresters until it reaches zero.

The dc-side DRU pole current $\left(I_{R d c, p}\right)$ reaches a peak value of $2 \mathrm{pu}$, which is well within the overcurrent capability of the diode rectifiers. The large ground fault current through the diode rectifier ground $\left(I_{R d c, g}\right)$ can also be clearly seen, with a value larger than $-1.5 \mathrm{pu}$. On the other hand, the MMC-2 dc side current $\left(I_{V d c 2}\right)$ reaches a value of 1.4 pu during fault recovery.

\section{B. Fault response with resistive DRU-HVdc grounding}

By using resistive grounding for the DRU converter, it is possible to limit the short circuit transient currents to adequate levels. However, resistive grounding could cause DRU converter overvoltages which would lead to somehow higher isolation requirements and higher stress to sourge arresters.

To analyze the effect of the resistive DRU grounding, a sensitive analysis has been carried out when a mid-point cable fault occurs between MMC-1 and DRU station. Fig. 15 shows the reduction of the maximum dc-fault current as a function of the DRU grounding resistance $\left(R_{D G}\right)$. This reduction occurs when $R_{D G}>1 \Omega$ and ceases when surge arresters increase their conduction at $R_{D G}>1000 \Omega$.

Fig. 15 also shows the increase of the maximum dc-voltages as a function of $R_{D G}$. Now dc-voltages increase from $R_{D G}=$ $1 \Omega$ to $R_{D G}=1000 \Omega$. Therefore, based on the sensitivity analysis, a resistance value of $R_{D G}=100 \Omega$ has been chosen.

With $R_{D G}=100 \Omega$, pole-to-pole voltages at MMC-1 and MMC-2 are below $1.1 \mathrm{pu}$, and shows a 1.3 pu overvoltage at DRU station. Surge arrester energies are bellow $500 \mathrm{~kJ}$, except the surge arresters of the dc-breaker which opens the cable current $I_{H 1, p}$, (Fig. 1). This surge arrester has a total dissipated energy of $2700 \mathrm{~kJ}$.

Figs. 16 to 17 show the dc-side voltages and currents for the same fault as the one considered in the previous section but including a DRU grounding resistor.

Maximum voltage values shown in Fig. 16 are almost the same as those in Fig. 12. However, Fig. 16 does not show the voltage oscillations seen in Fig. 12.

Fig. 17 also does away with the oscillations seen in Fig. 14, particularly in $I_{R d c}$, so clearly the grounding resistor cancels those oscillations. However, the use of a grounding resistor has only limited influence on the peak voltages and currents seen by the converters.

\section{Fault response with grounding resistor and WPP blocking}

This test case includes the use of a DRU grounding resistor and WPP reducing its production to zero once the dc-short circuit is detected by the WTGs. Once the short circuit is cleared, the WPP resumes production. The results are shown in Figs. 18 and 19.

Converter voltages in Fig. 18 do not show substantial differences from the previous two cases. However, Fig. 19 shows that currents $I_{R d c}$ go to zero when the WPP is blocked (i.e. its voltage is reduced so the HVdc-DRU does not conduct). Moreover the peak value of MMC-2 converter current $\left(I_{V d c 2}\right)$ is greatly reduced. Power through MMC-2 resumes $100 \mathrm{~ms}$ after the fault onset, however, in the previous two cases, active power is resumed in less than $20 \mathrm{~ms}$ after the fault onset.

\section{D. dcCB-less Strategy for Symmetric Monopole}

The fourth strategy consists on the use of WTG distance protection and MMC blocking without using dcCBs. Clearly, this strategy is the most cost efficient, as relatively costly $\mathrm{dcCB}$ are substituted less expensive dc disconnectors. Fault currents are drawn to zero by a combination of MMC converter and WPP blocking. Fault energy is partly absorbed by MMC capacitors, and partly dissipated in the DRU grounding resistor and system surge arresters. Once fault currents are zero (or very near to zero), the fast dc disconnectors are opened and a signal is sent to the WPP to resume power production.

The results for the same fault as that in previos sections are shown in Figs. 20 and 21. Fig. 20 shows that fault currents take longer than in the previous case to reach zero and hence fault clearing times are larger in this case. However, the rest of the currents are similar to those in previous cases. Fig. 21 shows that voltages are also very similar to previous cases. 

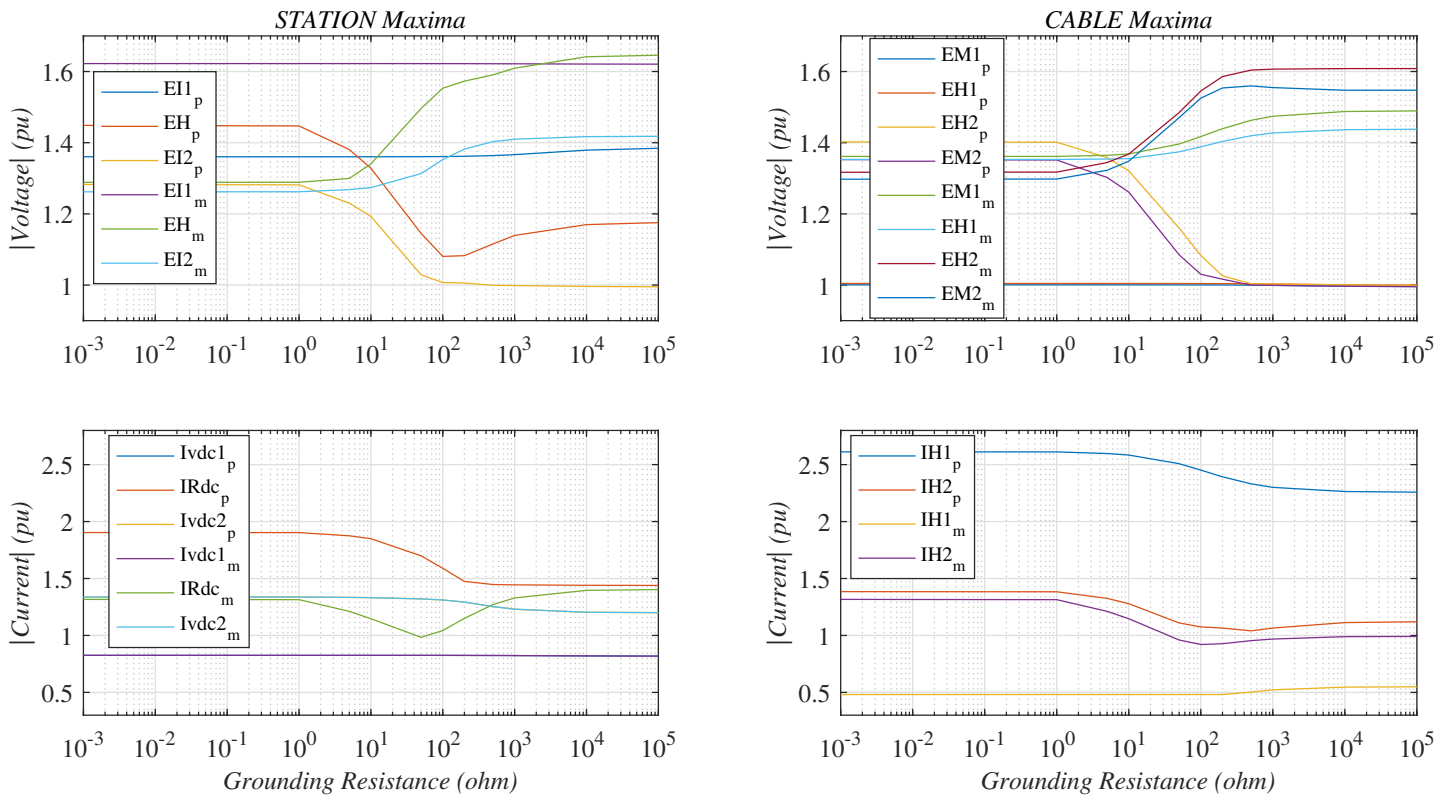

Fig. 15. MMC-1-DRU cable short-circuit: HVdc voltages (pu) as a function of DRU grounding resistance.
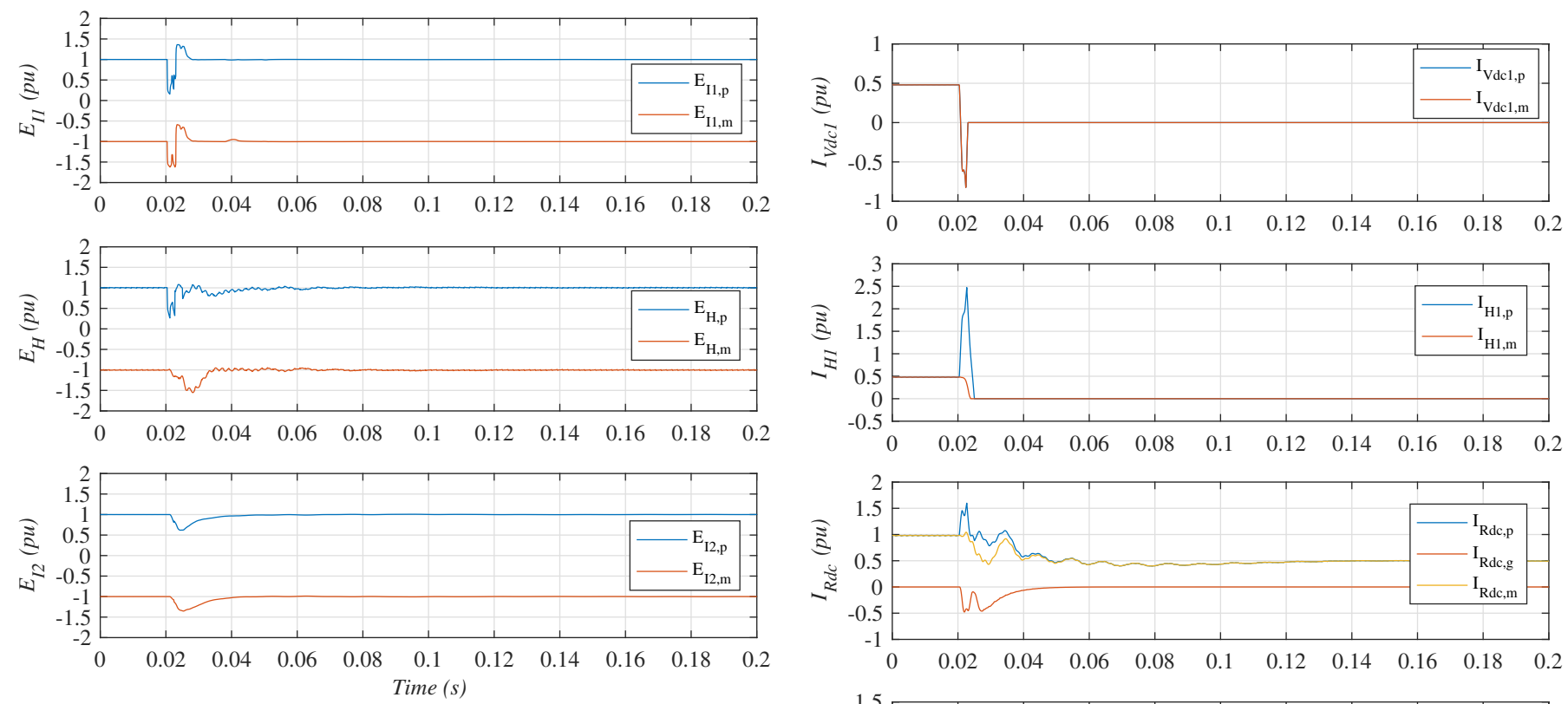

Fig. 16. Strategy 2: Converter voltages (pu). From top to bottom: MMC-1 dc-voltages; DRU dc-voltages; MMC-2 dc-voltages.

\section{E. Bipolar HVdc Fault Blocking with Hybrid MMCs}

Figs. 23 and 22 shows the response of the system in the event of a dc fault when the HVdc grid has a bipolar configuration. In this case, the $\mathrm{HVdc}$ grid is rigidly grounded at the dc-side and hybrid MMCs with 50\% of FB-SMs are used. Similarly to the previous cases, the MMC-2 is in power control mode and the MMC-1 regulates the HVdc voltage. When a pole-to-ground occurs at the positive pole at $t=0.02 \mathrm{~s}$, the dc voltage of the positive pole collapses, Fig. 22. However, due to the use of FB-SMs, the MMCs can continue their operation and avoid large overcurrents. As soon as the fault is detected,
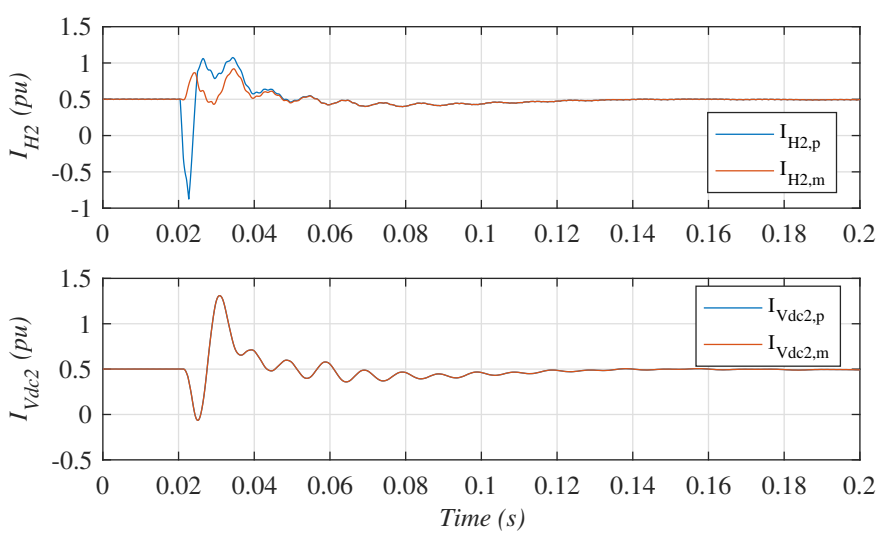

Fig. 17. Strategy 2: HVdc currents (pu). From top to bottom: MMC-1 dccurrents; DRU to cable-1 dc-breaker currents; DRU dc-currents; DRU to cable2 dc-breaker currents; MMC-2 dc-currents. 

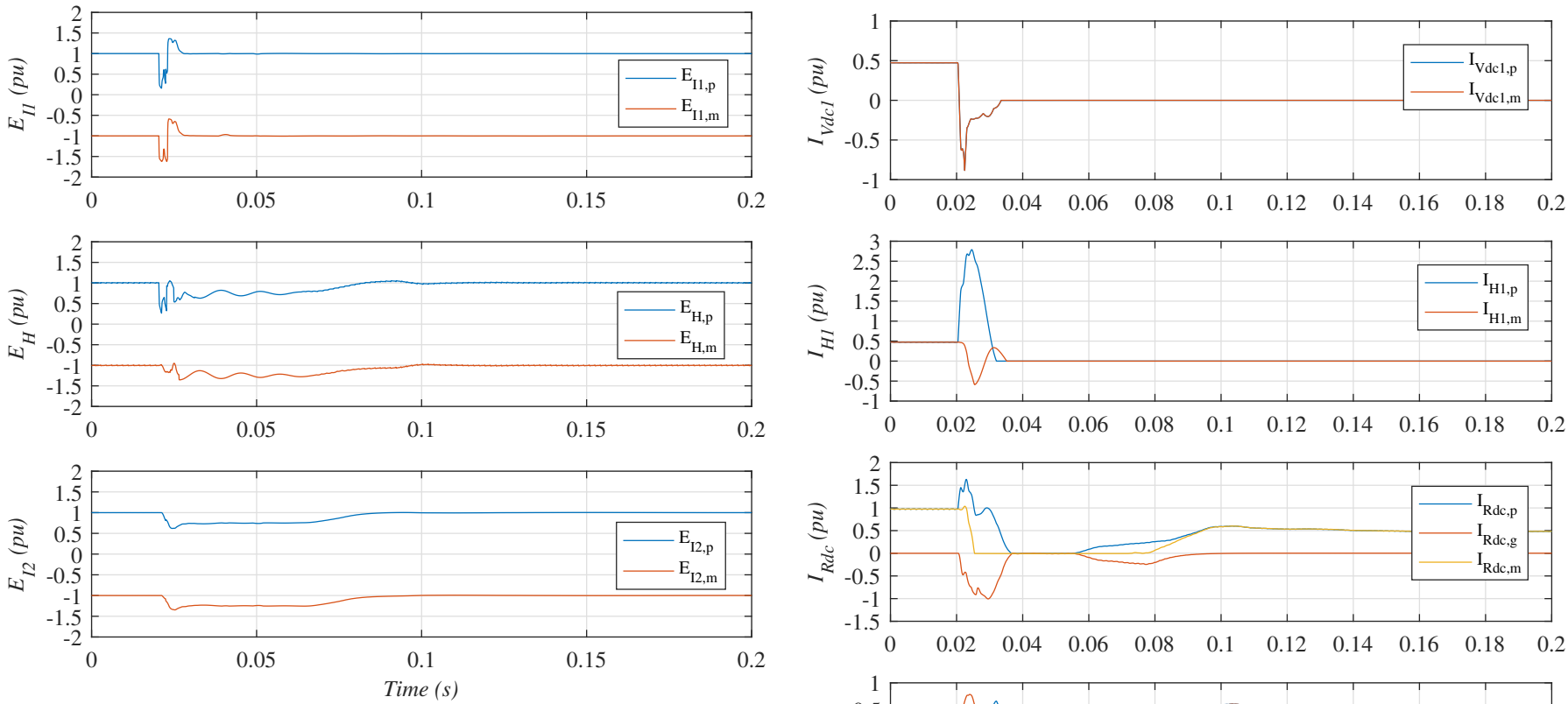

Fig. 18. Strategy 3: Converter terminal voltages (pu). From top to bottom: MMC-1 dc-voltages; DRU dc-voltages; MMC-2 dc-voltages.
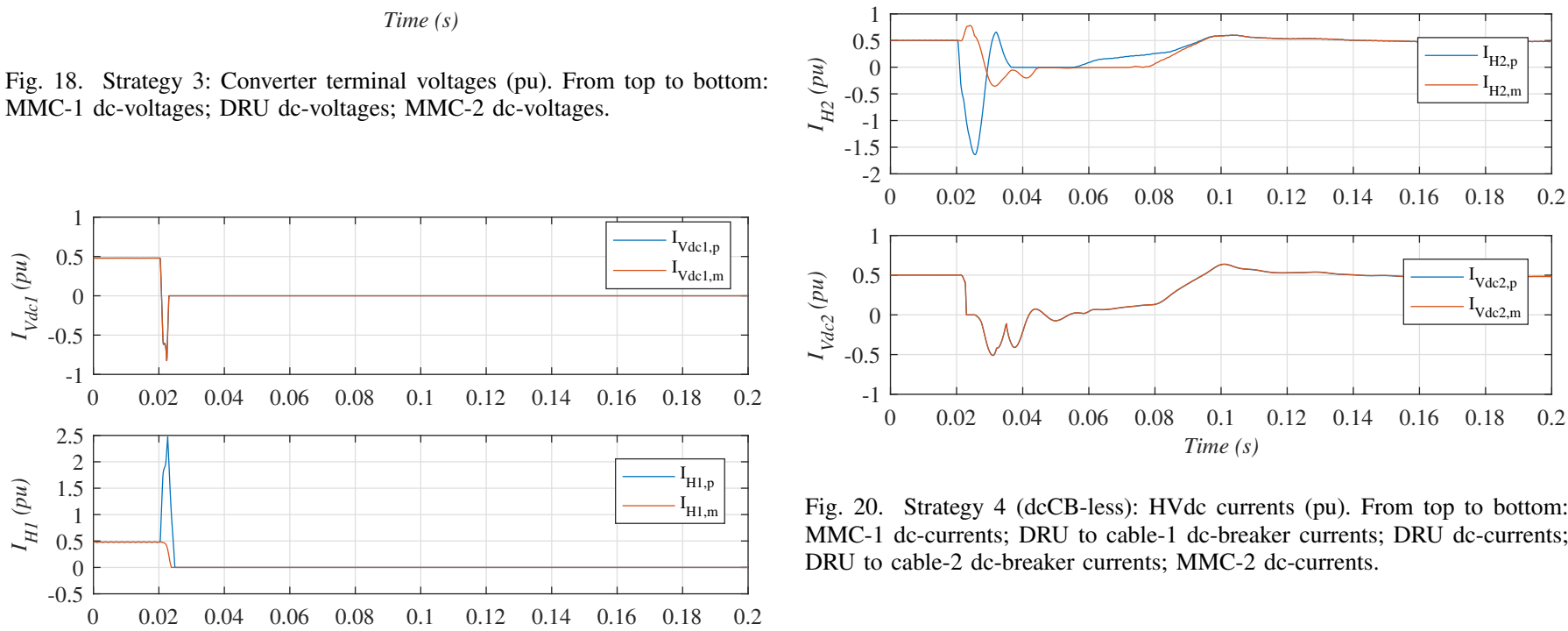

Fig. 20. Strategy 4 (dcCB-less): HVdc currents (pu). From top to bottom: MMC-1 dc-currents; DRU to cable-1 dc-breaker currents; DRU dc-currents; DRU to cable-2 dc-breaker currents; MMC-2 dc-currents.
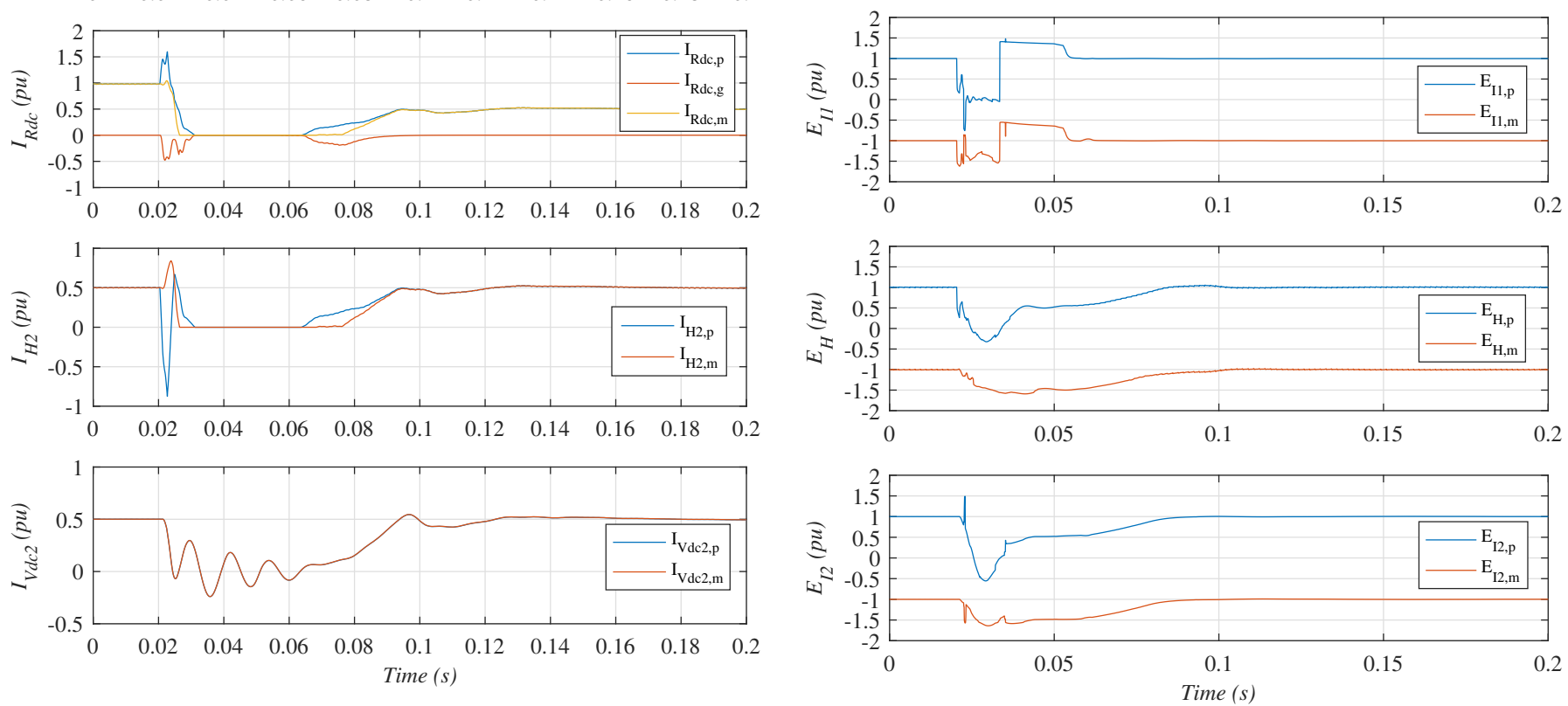

Fig. 19. Strategy 3: HVdc currents (pu). From top to bottom: MMC-1 dccurrents; DRU to cable-1 dc-breaker currents; DRU dc-currents; DRU to cable2 dc-breaker currents; MMC-2 dc-currents.

Fig. 21. Strategy 4 (dcCB-less): HVdc voltages (pu). From top to bottom: MMC-1 dc-voltages; DRU dc-voltages; MMC-2 dc-voltages. 

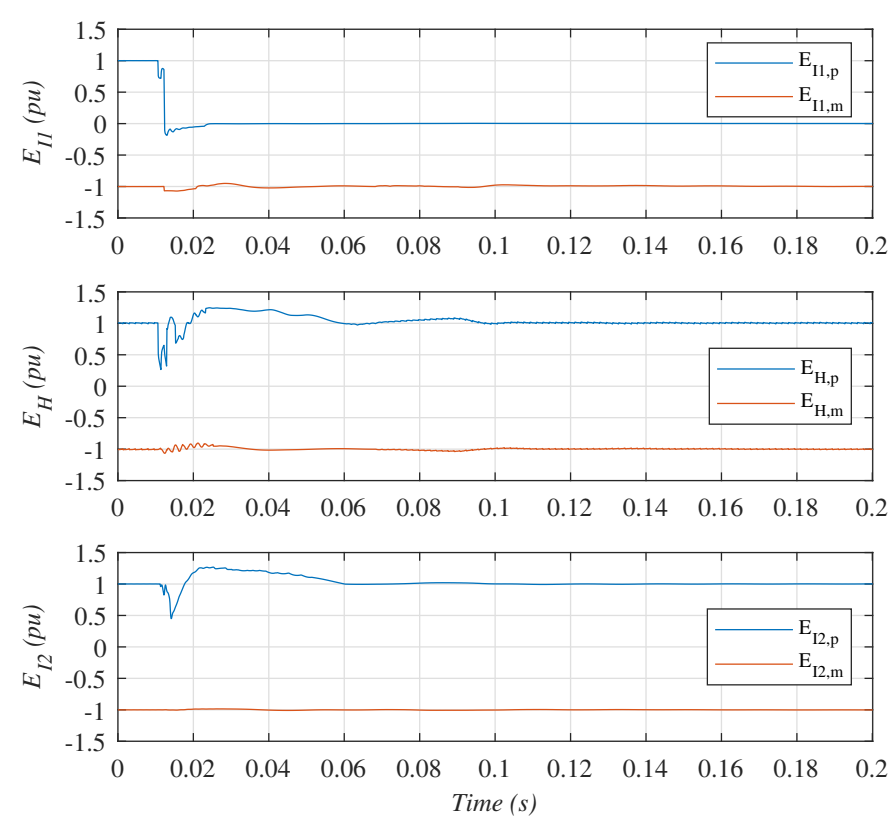

Fig. 22. Strategy 5 (Bipolar). MMC-1 short-circuit: voltages (pu). From top to bottom: MMC-1 dc-voltages; DRU dc-voltages; MMC-2 dc-voltages.

the MMC-2 connected of the positive pole changes its current reference to zero. Moreover, the MMC-1 of the positive pole changes to power control mode with a current reference of zero too. In this way the fault current fed from both MMC stations drops to zero as seen in the first and fifth graphs of Fig. 23. Additionally, the WPP also stops injecting power to the HVdc grid so none of the three power stations feeds the fault (third graph). At this time, the dc switches are opened to isolate the faulty cable. Next both MMC-2 converters change to dc voltage control and the MMC-1 connected to the negative pole change to power control and the WPP resumes its operation. With this configuration, the negative pole is continuously in operation so ac grid 1 is not completely disconnected form the $\mathrm{HVdc}$ grid. Therefore, there is not a complete loss of power as in the monopolar configuration.

\section{Comparison of Considered Strategies}

The comparison of the considered strategies is carried out in terms of maximum pole-to-ground and pole-to-pole voltages, maximum currents during the fault, surge arrester dissipated energy and fault recovery times.

Table II shows the maximum pole voltage values for the each fault clearing strategy. The maximum pole voltage is 1.62 $\mathrm{pu}$ for the four symmetric monopole cases. It is worth noting that the DRU healthy pole voltage reaches 1.59 pu. Clearly, the different parts of the system should be designed for the isolation levels in Table II. The WTG voltages are within limits in all cases (up to $1.1 \mathrm{pu}$ ).

Table III shows the maximum pole-to-pole voltages, which determine the number of required diodes for the DRU valves $\left(E_{H}\right)$. The sum of the cell voltages of each MMC arm is equal to the pole-to-pole voltage, therefore, the MMC power switches can withstand up to 2 pu pole-to-pole voltage without increasing the number of cells, albeit with increased isolation
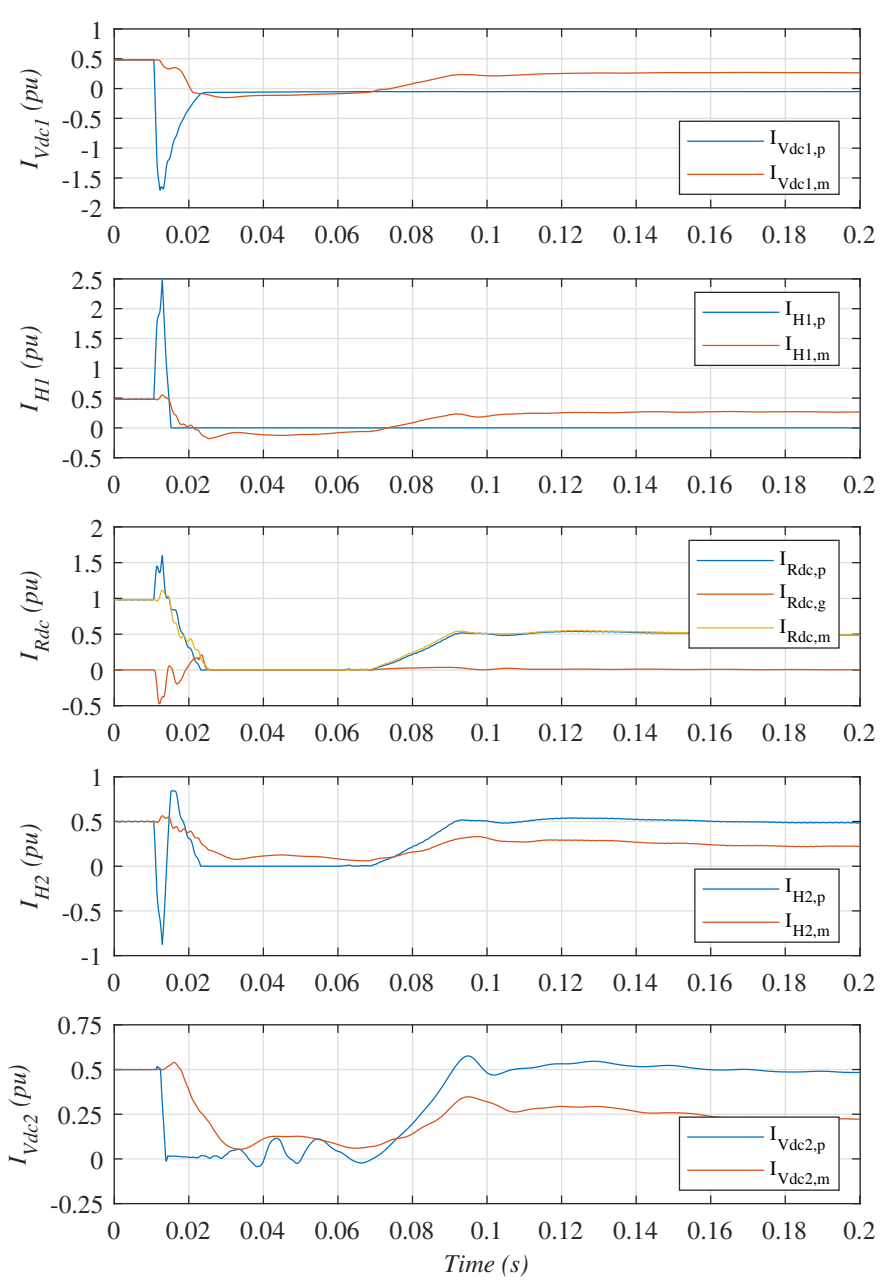

Fig. 23. Strategy 5 (Bipolar). MMC-1 short-circuit: currents(pu). From top to bottom: MMC-1 dc-currents; DRU to cable-1 dc-breaker currents; DRU dc-currents; DRU to cable-2 dc-breaker currents; MMC-2 dc-currents.

requirements. The voltage $E_{H}$ shows that the DRUs valves need to be rated to $1.32 \mathrm{pu}$ voltage for the first two strategies and only by a $7 \%$ for the dcCB-less strategy.

Table IV shows the maximum values of currents for the considered test cases. The currents $I_{V d c 1, p, m}$ and $I_{V d c 2, p, m}$ show the current peak levels that the MMCs shall support in order to avoid damage. $I_{H 1, p, m}$ and $I_{H 2, p, m}$ show the maximum currents through the $\mathrm{HVdc}$ cables. The worst results $(2.61 \mathrm{pu})$ are obtained for strategy 4 . In any case, the duration of the peak current is shorter than $5 \mathrm{~ms}$ which is not enough to damage the cable. $I_{R d c, p, g, m}$ show the peak current levels at DRU terminals. The largest fault current through the DRUs is obtained for the solid DRU grounding. However, a 1.9 pu current for a diode rectifier for a short period of time $(13 \mathrm{~ms})$ is perfectly acceptable. The maximum current peak of WTGs $I_{W T}$ is 1.33 pu for strategy 3. The overcurrent lasts for a few milliseconds, and is within the short time overload capability of high power IGBTs. However, this possible overcurrent should be taken into account when designing the WTG converter.

Table $\mathrm{V}$ shows the surge arrester dissipated energy. In any configuration, the surge arresters disipate energy in order to 
TABLE II

MAXIMUM POLE VOLTAGE VALUES (PU)

\begin{tabular}{llllllll}
\hline & $E_{I 1, p}$ & $E_{I 1, m}$ & $E_{H, p}$ & $E_{H, m}$ & $E_{I 2, p}$ & $E_{I 2, m}$ & $V_{W T}$ \\
\hline Solid DRU-MMC ground & 1.36 & -1.62 & 1.45 & -1.28 & 1.27 & -1.26 & 1.1 \\
Resistive DRU-HVdc grounding & 1.36 & -1.62 & 1.08 & -1.55 & 1.01 & -1.35 & 1.04 \\
Grounding resistor and WPP blocking & 1.36 & -1.62 & 1.06 & -1.34 & 1.01 & -1.35 & 1.0 \\
WTG distance protection and MMC blocking & 1.4 & -1.62 & 1.06 & -1.59 & 1.49 & -1.64 & 1.07 \\
Bipolar & 1.0 & -1.06 & 1.3 & -1.06 & 1.04 & -1.05 & 1.0 \\
\hline
\end{tabular}

TABLE III

MAXIMUM POLE-TO-POLE VOLTAGE VALUES (PU)

\begin{tabular}{llll}
\hline & $E_{I 1}$ & $E_{H}$ & $E_{I 2}$ \\
\hline Solid DRU-MMC ground & 1.1 & 1.32 & 1.04 \\
Resistive DRU-HVdc grounding & 1.1 & 1.32 & 1.04 \\
Grounding resistor and WPP blocking & 1.1 & 1.15 & 1.02 \\
WTG distance protection and MMC blocking & 1.18 & 1.07 & 1.52 \\
Bipolar & 1.0 & 1.13 & 1.02 \\
\hline
\end{tabular}

TABLE IV

MAXIMUM CURRENT VALUES (PU)

\begin{tabular}{|c|c|c|c|c|c|c|c|c|c|c|c|c|}
\hline & $I_{V d c 1, p}$ & $I_{V d c 1, m}$ & $I_{H 1, p}$ & $I_{H 1, m}$ & $I_{R d c, p}$ & $I_{R d c, g}$ & $I_{R d c, m}$ & $I_{H 2, p}$ & $I_{H 2, m}$ & $I_{V d c 2, p}$ & $I_{V d c 2, m}$ & $I_{W T}$ \\
\hline Solid DRU-MMC ground & -0.81 & -0.81 & 2.55 & 0.5 & 1.9 & -1.4 & 1.31 & 1.38 & 1.32 & 1.34 & 1.34 & 1.2 \\
\hline Resistive DRU-HVdc grounding & -0.82 & -0.82 & 2.5 & 0.5 & 1.6 & -0.48 & 1.04 & 1.08 & 0.91 & 1.31 & 1.31 & 1.19 \\
\hline Grounding resistor and WPP blocking & -0.8 & -0.8 & 2.5 & 0.5 & 1.6 & -0.48 & 1.04 & -0.88 & 0.83 & 0.6 & 0.6 & 1.33 \\
\hline $\begin{array}{l}\text { WTG distance protection and MMC } \\
\text { blocking }\end{array}$ & -0.88 & -0.88 & 2.61 & -0.59 & 1.62 & -1.0 & 1.0 & -1.64 & 0.78 & 0.62 & 0.62 & 1.17 \\
\hline Bipolar & -1.67 & 0.5 & 2.39 & 0.5 & 1.55 & -0.47 & 1.11 & 0.77 & -0.52 & 0.95 & 0.95 & 1.1 \\
\hline
\end{tabular}

TABLE V

Surge ARrester Dissipated Energy (KJ)

\begin{tabular}{|c|c|c|c|c|c|c|c|c|c|c|c|c|}
\hline & $W_{I 1, p}$ & $W_{I 1, m}$ & $W_{M 1, p}$ & $W_{M 1, m}$ & $W_{H 1, p}$ & $W_{H 1, m}$ & $W_{H 2, p}$ & $W_{H 2, m}$ & $W_{M 2, p}$ & $W_{M 2, m}$ & $W_{I 2, p}$ & $W_{I 2, m}$ \\
\hline Solid DRU-MMC ground & 0.3 & 332.6 & 242.4 & 126.52 & 3279 & 0.0 & 0.0 & 0.0 & 0.0 & 0.0 & 35.8 & 36.2 \\
\hline Resistive DRU-HVdc grounding & 0.3 & 333.5 & 242.3 & 125.7 & 2690 & 0.0 & 0.0 & 0.0 & 0.0 & 0.0 & 35.8 & 36.2 \\
\hline Grounding resistor and WPP blocking & 0.3 & 333.5 & 242.3 & 125.7 & 2626 & 0.0 & 0.0 & 0.0 & 0.0 & 0.0 & 35.8 & 36.2 \\
\hline WTG distance protection and MMC blocking & 4.09 & 276.7 & 2.9 & 0.0 & 0.0 & 0.0 & 0.0 & 0.0 & 0.0 & 0.0 & 34.7 & 2316 \\
\hline Bipolar & 0.2 & 0.2 & 0.0 & 0.0 & 2764 & 0.0 & 0.0 & 0.0 & 0.0 & 0.0 & 0.2 & 0.2 \\
\hline
\end{tabular}

TABLE VI

FAULT RECOVERY TIMES

\begin{tabular}{lll}
\hline & $\begin{array}{l}\text { Time from fault } \\
\text { detection to } \\
\text { fault clearing }(\mathrm{ms})\end{array}$ & $\begin{array}{l}\text { Time to recover } \\
\text { previous power } \\
\text { generation }(\mathrm{ms})\end{array}$ \\
\hline Solid DRU-MMC ground & 3 & 80 \\
Resistive DRU-HVdc grounding & 3 & 80 \\
Grounding resistor and WPP blocking & 2 & 70 \\
WTG distance protection and MMC blocking & 10.5 & 87 \\
Bipolar & 3 & 80 \\
\hline
\end{tabular}

maintain the voltages in safe limits. The worse case is the symmetric monopole with solid ground $(3279 \mathrm{~kJ})$. When the DRU grounding resistor is used, there is a reduction on surge arrester energy. In any case, it is worth noting that different strategies lead to subtantially different surge arrester use.

Finally, table VI shows the fault recovery times for each strategy. As expected, the longest clearing time $(13 \mathrm{~ms})$ is obtained with a symmetric monopole with both WPP and MMC blocking. In this case, HVdc fault clearing time is $13 \mathrm{~ms}$, with relatively fast power recovery $(80 \mathrm{~ms})$, which is within the limits fixed in "(ENTSO-E) Network Code for
HVdc connections" (0.14 s).

\section{CONCLUSIONS}

This paper includes the study of five protection strategies. Three of them require the use of $\mathrm{dcCBs}$ for the symmetric monopole connection. When both WPP and MMC converters are blocked, dcCBs can be substituted by fast disconnectors (or dcCBs of a much smaller rating). For this approach, it is required that the WTGs include distance protection features to distinguish between ac-collector faults and HVdc faults. For the sake of completeness, a case including hybrid MMCs in a bipolar configuration with full blocking capability have also been studied.

For each strategy, the maximum voltages, currents, surge arrester energy and fault clearing times have been studied. The comparative advantages and disadvantages of each approach are shown in table VII.

Moreover, this paper has been shown that it is possible to use a protection strategy for symmetric monopole connectors without use of $\mathrm{dcCBs}$, at the expense of longer clearing times and higher energy dissipated in surge arresters. This solution 
TABLE VII

ADVANTAGES AND DISAVANTAGES OF THE CONSIDERED CONFIGURATIONS

\begin{tabular}{lll}
\hline & Advantages & Disadvantages \\
\hline Solid DRU-MMC ground & $\begin{array}{l}\text { well known in literature } \\
\text { Communication to WPP to clear faults not required }\end{array}$ & $\begin{array}{l}\text { requires 35\% extra DRU isolation } \\
\text { dc-circuit breaker required }\end{array}$ \\
\hline $\begin{array}{l}\text { Resistive DRU-HVdc } \\
\text { grounding }\end{array}$ & $\begin{array}{l}\text { extra DRU isolation not required } \\
\text { Communication to WPP to clear faults not required }\end{array}$ & dc-circuit breaker required \\
\hline $\begin{array}{l}\text { Grounding resistor } \\
\text { and WPP blocking }\end{array}$ & extra DRU isolation not required & $\begin{array}{l}\text { Communication to WPP to clear faults required } \\
\text { dc-circuit breaker required }\end{array}$ \\
\hline $\begin{array}{l}\text { WTG distance protection } \\
\text { and MMC blocking }\end{array}$ & dc-circuit breaker not required & $\begin{array}{l}\text { longer clearing times } \\
\text { Communication to WPP to clear faults required }\end{array}$ \\
\hline & $\begin{array}{l}\text { dc-circuit breaker not required } \\
\text { additional redundancy }\end{array}$ & $\begin{array}{l}\text { Increased cost } \\
\text { requires 20\% extra DRU isolation }\end{array}$ \\
\hline
\end{tabular}

TABLE VIII

SYSTEM PARAMETERS

Wind Turbines

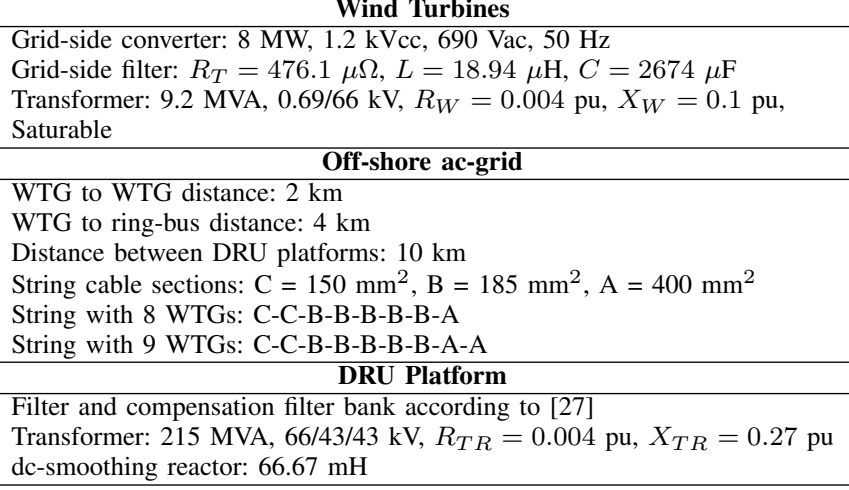

is particularly attractive as it is the less costly and allows active power flow through the healthy cable in a relatively short period of time after the fault.

\section{APPENDIX A SYSTEM PARAMETERS}

Table VIII shows the parameters values of the system components.

\section{REFERENCES}

[1] R. Blasco-Gimenez, S. Añó-Villalba, J. Rodríguez-D’Derlée, F. Morant, S. Bernal-Perez, Distributed Voltage and Frequency Control of Offshore Wind Farms Connected With a Diode-Based HVdc Link, Power Electronics, IEEE Transactions on 25 (12) (2010) 3095-3105.

[2] Peter Menke, New Grid Access Solutions for Offshore Wind Farms, in: EWEA Offshore, Copenhaguen, 2015.

URL http://www.ewea.org/offshore2015/conference/allposters/PO208. pdf

[3] T. Hammer, S. Seman, P. Menke, F. Hacker, B. Szangolies, J. Meth, J. Dorn, K. Loppach, R. Zurowski, Diode-Rectifier HVDC link to onshore power systems: Dynamic performance of wind turbine generators and Reliability of liquid immersed HVDC Diode Rectifier Units, in: CIGRE Conference Technical Committee B4, 2016.
[4] S. Bernal-Perez, S. Añó-Villalba, R. Blasco-Gimenez, J. RodriguezD'Derlee, Efficiency and Fault Ride-Through Performance of a DiodeRectifier- and VSC-Inverter-Based HVDC Link for Offshore Wind Farms, IEEE Transactions on Industrial Electronics 60 (6) (2013) 2401 -2409. doi:10.1109/TIE.2012.2222855.

[5] Peter Menke, Rainer Zurowski, Timo Christ, Slavomir Seman, Gerald Giering, Thomas Hammer, Wolfgang Zink, Felix Hacker, Denis Imamovic, Jan Thisted, Paul Brogan, Nikolaus Goldenbaum, Second Generation DC Grid Access for Large Scale Offshore Wind Farms, in: 14th International Workshop on Large-Scale Integration of Wind Power into Power Systems as well as on Transmission Networks for Offshore Wind Power Plants, Brussels, 2015, pp. 1-6.

[6] P. Menke, Major breakthrough in DC grid access for large scale offshore wind farms, in: EWEA Offshore Conference, Copenhagen, 2015.

[7] X. Han, W. Sima, M. Yang, L. Li, T. Yuan, Y. Si, Transient Characteristics Under Ground and Short-Circuit Faults in a $500 \mathrm{kV}$ MMC-Based HVDC System With Hybrid DC Circuit Breakers, IEEE Trans. Power Delivery 33 (3) (2018) 1378-1387.

[8] S. Wenig, M. Goertz, C. Hirsching, M. Suriyah, T. Leibfried, On FullBridge Bipolar MMC-HVDC Control and Protection for Transient Fault and Interaction Studies, IEEE Transactions on Power Delivery 33 (6) (2018) 2864-2873.

[9] Y. Liu, M. Huang, X. Zha, H. H.-C. Iu, Short-Circuit Current Estimation of Modular Multilevel Converter Using Discrete-Time Modeling, IEEE Trans. Power Electron. 34 (1) (2019) 40-45.

[10] M. Langwasser, G. De Carne, M. Liserre, M. Biskoping, Fault Current Estimation in Multi-Terminal HVdc Grids Considering MMC Control, IEEE Trans. Power Syst. 34 (3) (2019) 2179-2189.

[11] N. A. Belda, C. A. Plet, R. P. P. Smeets, Analysis of Faults in Multiterminal HVDC Grid for Definition of Test Requirements of HVDC Circuit Breakers, IEEE Trans. Power Delivery 33 (1) (2018) 403-411.

[12] G. Tang, Z. Xu, A LCC and MMC hybrid HVDC topology with DC line fault clearance capability, International Journal of Electrical Power \& Energy Systems 62 (2014) 419-428. doi:10.1016/j.ijepes.2014.04.045. URL http://www.sciencedirect.com/science/article/pii/ S0142061514002403

[13] H. Rao, Y. Zhou, S. Xu, X. Cai, W. Cao, Y. Xu, C. Ren, Key technologies of ultra-high voltage hybrid LCC-VSC MTDC systems, CSEE Journal of Power and Energy Systems 5 (3) (2019) 365-373. doi:10.17775/CSEEJPES.2019.01140.

[14] Z. Zhu, W. Gong, J. Chen, F. Zhang, W. Wang, W. Li, HIL Testing of an LCC-MMC Multi-terminal HVDC System in Various Operating Modes, in: Proceedings of the International Conference on Power Systems Transients 2019 (IPST 2019), Perpignan, 2019.

[15] N. M. Haleem, A. D. Rajapakse, A. M. Gole, I. T. Fernando, Investigation of Fault Ride-Through Capability of Hybrid VSC-LCC MultiTerminal HVDC Transmission Systems, IEEE Transactions on Power Delivery 34 (1) (2019) 241-250, conference Name: IEEE Transactions on Power Delivery. doi:10.1109/TPWRD.2018.2868467. 
[16] CENELEC, CLC/TS 50654-1:2020 "HVDC Grid Systems and connected Converter Stations - Guideline and Parameter Lists for Functional Specifications - Part 1: Guidelines" (2020).

[17] M. Wang, W. Leterme, G. Chaffey, J. Beerten, D. Van Hertem, Pole Rebalancing Methods for Pole-to-Ground Faults in Symmetrical Monopolar HVDC Grids, IEEE Transactions on Power Delivery 34 (1) (2019) 188-197, conference Name: IEEE Transactions on Power Delivery. doi:10.1109/TPWRD.2018.2853704.

[18] P. Rault, M. Yazdani, S. Dennetière, C. Wikström, H. Saad, N. Johannesson, Real-time simulation with an industrial DCCB controller in a HVDC grid, in: Proceedings of the International Conference on Power Systems Transients 2019 (IPST 2019), Perpignan, 2019.

[19] S. Añó-Villalba, R. Blasco-Gimenez, S. Bernal-Perez, E. Belenguer, Wind power plant integration in voltage source converter HVdc grids with voltage droop control, Mathematics and Computers in Simulation 146 (2018) 186-199. doi:10.1016/j.matcom.2016.12.007.

URL S037847541730006X

http://www.sciencedirect.com/science/article/pii/

[20] R. Li, L. Yu, L. Xu, G. P. Adam, DC Fault Protection of Diode Rectifier Unit Based HVDC System Connecting Offshore Wind Farms, in: 2018 IEEE Power Energy Society General Meeting (PESGM), 2018, pp. 1-5, iSSN: 1944-9933. doi:10.1109/PESGM.2018.8586510.

[21] R. Li, L. Yu, L. Xu, Offshore AC Fault Protection of Diode Rectifier Unit-Based HVdc System for Wind Energy Transmission, IEEE Transactions on Industrial Electronics 66 (7) (2019) 5289-5299. doi:10.1109/TIE.2018.2869357.

[22] S. Dennetière, S. Nguefeu, H. Saad, J. Mahseredjian, Modeling of modular multilevel converters for the France-Spain link, in: Proceedings of the International Conference on Power Systems Transients (IPST'13), Vancouver, Canada, 2013, pp. 1-7.

[23] R. Vidal-Albalate, H. Beltran, A. Rolán, E. Belenguer, R. Peña, R. Blasco-Gimenez, Analysis of the Performance of MMC Under Fault Conditions in HVDC-Based Offshore Wind Farms, IEEE Transactions on Power Delivery 31 (2) (2016) 839-847. doi:10.1109/TPWRD.2015.2468171.

[24] W. Leterme, P. Tielens, S. De Boeck, D. Van Hertem, Overview of Grounding and Configuration Options for Meshed HVDC Grids, IEEE Transactions on Power Delivery PP (99) (2014) 1-1. doi:10.1109/TPWRD.2014.2331106.

[25] L. Shi, G. P. Adam, R. Li, L. Xu, Enhanced Control of Offshore Wind Farms Connected to MTDC Network Using Partially Selective DC Fault Protection, IEEE Journal of Emerging and Selected Topics in Power Electronics (2020) 1-1Conference Name: IEEE Journal of Emerging and Selected Topics in Power Electronics. doi:10.1109/JESTPE.2020.2985129.

[26] T. Augustin, I. Jahn, S. Norrga, H.-P. Nee, Transient behaviour of VSC-HVDC links with DC breakers under faults, in: 2017 19th European Conference on Power Electronics and Applications (EPE'17 ECCE Europe), 2017, pp. P.1-P.10, iSSN: null. doi:10.23919/EPE17ECCEEurope.2017.8099248.

[27] M. Szechtman, T. Wess, C. V. Thio, First benchmark model for HVDC control studies, Electra 135 (4) (1991) 54-67.

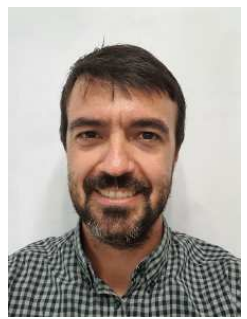

Jaime Martínez Turégano received the M.S. degree in electronics and automatic control engineering from the Universitat Politècnica de València, Valencia, Spain, in 2014. From 2015 to 2016, he worked as a control software development and validation engineer for the aerospace sector. He is currently working toward the Ph.D. degree in the Institute of Control and Industrial Informatics of Universitat Politècnica de València. His research interests include Control of WPPs and HVdc diode rectifiers.

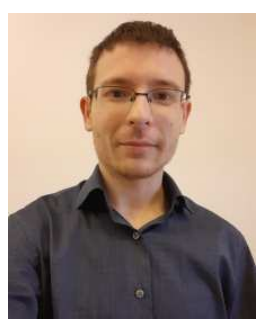

Ricardo Vidal-Albalate received the M.Sc. degree in industrial engineering and the Ph.D in electrical engineering from the Universitat Jaume I (UJI), Castello de la Plana, Spain, in 2010 and 2017, respectively. He was a visiting scholar for 6 months at the Dept. of Electrical and Electronic Engineering of the University of Nottingham, U.K., in 2014. He has been a Lecturer with UJI since 2013. His research interests include MMCs for HVDC grids and grid integration of wind power.

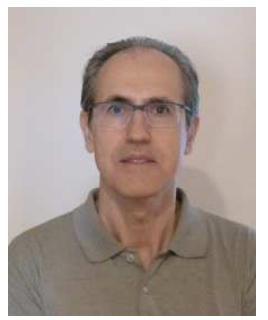

Salvador Añó-Villalba received the M.Sc.and Ph.D. degrees in electrical engineering from the Universitat Politecnica de Valencia (UPV) in 1988 and 1996, respectively. From 1987 to 1989, he was with the R\&D Department of Electronic Traffic S.A. to develop a measuring and automation system for street lighting. In 1988, he joined the Department of Electrical Engineering of UPV where he is currently an Associate Professor. He has been a consultant to Iberdrola S.A. on high-impedance faults, load forecasting, and neutral break detection. His current research interests include wind energy integration and electrical machines.

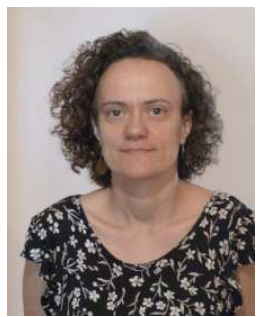

Soledad Bernal-Perez holds an MEng Degree in Electrical Engineering from the Universitat Politecnica de Valencia. Since 2003, she has been a Lecturer with the Department of Electrical Engineering, Universitat Politècnica de València. Her areas of research interest are control strategies for connection of off-shore wind farms to HVDC grids and stability issues and control interaction between diode rectifiers, MMC converters and on-shore grid.

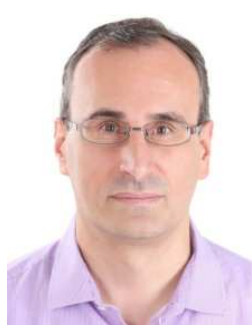

Ramon Blasco-Gimenez (S'94-M'96-SM'10) obtained his BEng degree in Electrical Engineering from Universitat Politècnica de València (Spain) in 1992 and his PhD degree in Electrical and Electronic Engineering from the University of Nottingham (UK) in 1996. From 1992 to 1995 he was a Research Assistant at the Dept. of Electrical and Electronic Engineering of the University of Nottingham. In 1996 he joined the Dept. of Systems Engineering and Control of Universitat Politècnica de València, where he is currently a Professor. His research interests include HVdc diode rectifiers, Control of HVdc systems, Wind Power Generation and Grid Integration of Renewable Energy Systems. Dr BlascoGimenez has been a co-recipient of the 2004 IEEE Transactions on Industrial Electronics Best Paper Award. 